\title{
REVIEWS
}

\section{Preparation and Properties of Polymer-grafted Carbon Nanotubes and Nanofibers}

\author{
Norio TsUBOKAWA ${ }^{\dagger}$ \\ Department of Material Science and Technology, Faculty of Engineering, Niigata University; \\ Center for Transdisciplinary Research, Niigata University, 8050, Ikarashi 2-nocho, Niigata 950-2181, Japan
}

(Received May 25, 2005; Accepted June 1, 2005; Published September 15, 2005)

\begin{abstract}
Recent advances in surface grafting of polymers onto carbon nanotubes (CNT) and nanofibers, such as vapor grown carbon fiber (VGCF), are reviewed. The grafting of polymers onto these surfaces was achieved by (1) the "grafting onto" method, (2) "polymer reaction" method, (3) "grafting from" method, and (4) "stepwise growth" method by dendrimer synthesis methodology. For the grafting of polymers, surface functional groups, such as carboxyl and phenolic hydroxyl groups, previously introduced onto the surface by oxidation with nitric acid, were used as grafting sites. These functional groups were converted into various initiating groups and surface initiated graft polymerization was achieved. The graphene sheet (polycondensed aromatic rings) of CNT and VGCF were used as grafting sites by using ligand-exchange reaction with polymers containing ferrocene moieties. The radical trapping nature of CNT and VGCF surface was used for the grafting of polymers. Dispersibility in solvents for good solvents of grafted polymer was remarkably improved by the surface grafting of polymers onto CNT and VGCF surfaces. The response of electric resistance of the composite prepared from polymer-grafted CNT and VGCF to solvent vapor and temperature is discussed. [DOI 10.1295/polymj.37.637]

KEY WORDS Carbon Nanotube / Vapor Grown Carbon Fiber / Graphene Sheet / Surface Grafting of Polymer / Dispersibility / Composite / Electric Property /
\end{abstract}

Carbon nanotubes (CNTs) are of considerable interest for applications to fabricating new engineering materials, because they have unique chemical, physical, and structure properties. ${ }^{1-4}$ Among many different applications, a composite of CNT with polymer has been extensively investigated. ${ }^{4-8}$ The important problem for preparation of composites with polymers is the dispersion, compatibilization, and stabilization of CNT in the polymer matrices. Especially, singlewalled CNT (SW-CNT) is a strikingly inert material and usually in the form of bundles. To solve the problem, surface modification of CNT has been widely investigated. The covalent attachment of polymers, grafting of polymers, onto CNT is very effective because grafted polymers on the surface prevent the aggregation of CNT. Therefore, modification of CNT surface by grafting of polymers has been widely investigated by many researchers.

Vapor grown carbon fiber (VGCF) is a new class of carbon nanofiber different from carbon nano-tube in its method of production and lower cost. It is also different from the conventional pitch-based and poly(acrylonitrile)-based carbon fiber in nano-sized diameter. ${ }^{9}$ VGCF is generaly by the form of annular carbon layers arranged like a tree ring structure. The carbon rods have a high aspect ratio and nano-sized diameter ranging from 50 to $200 \mathrm{~nm}$, which is between those of conventional carbon fibers $(5-10 \mu \mathrm{m})$ and of carbon nanotubes $(1-50 \mathrm{~nm}) .{ }^{10}$ Due to unique physical properties, such as excellent thermal and electrical conductivity, and good mechanical behavior, VGCF is of considerable interest. ${ }^{11,12}$

VGCF is usually used as reinforcement, adsorbent, and conductive filler. Recently, it is used in batteries for electrode and separator. ${ }^{13,14}$ In most cases, it is used in the form of composite where the polymer is needed as matrices. However, the fibers intertwine, because of the very low surface free energy, nanosize, and low bulk density.

Therefore, it is difficult to disperse CNT and VGCF in polymer matrix uniformly. It is desirable that the polymers are covalently bonded to CNT and VGCF surfaces in preparation of composites with CNT and VGCF. The surface grafting of polymers provides the best possible adhesion and allows for optimal transfer of stress from the matrix to the fibers.

In the present review, our recent research topics on the surface grafting of polymers onto CNT and VGCF surfaces by several methods, as schematically shown in Figure 1, the recent advances for the surface grafting of CNT, and the dispersibility and the electric properties of polymer-grafted CNT and VGCF are described.

${ }^{\dagger}$ To whom correspondence should be addressed (E-mail: ntsuboka@eng.niigata-u.ac.jp). 

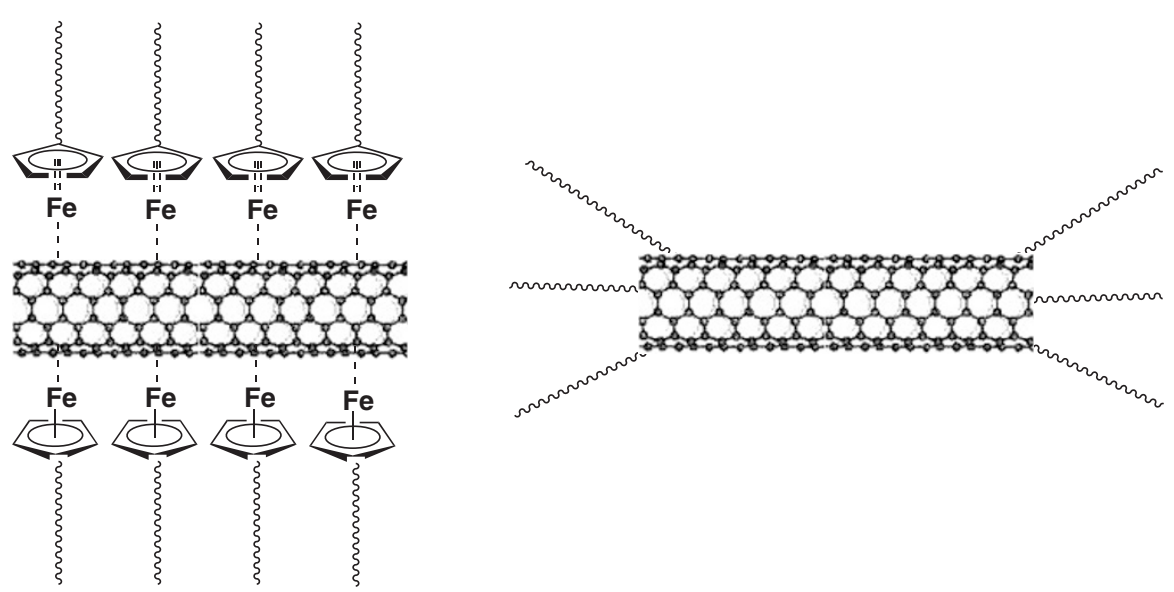

Figure 1. Grafting of polymers onto the surface of carbon nanotube and nanofiber.

\section{METHODOLOGY OF SURFACE GRAFTING OF POLYMERS ONTO CARBON NANOTUBE AND NANOFIBER}

Several methodologies have been developed for the preparation of conventional graft and block copolymers and we have applied these methodologies to the grafting of polymers onto carbon black surface. ${ }^{15,16}$ In general, one of the following principles, shown in Scheme 1, may be also applied to prepare polymer-grafted carbon nanotubes and nanofibers.

(1) "Grafting onto" method: the grafting is achieved by the termination of growing polymer radical, cation, and anion, formed during the polymeriza-

(1) "Grafting onto" method

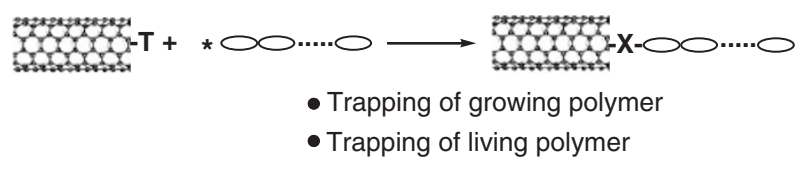

(2) "Polymer reaction" method

- Trapping of living polymer

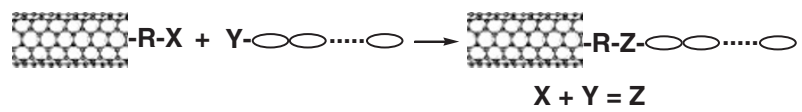

(3) "Grafting from" method

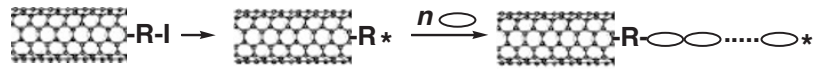

(4) "Stepwise growth" method

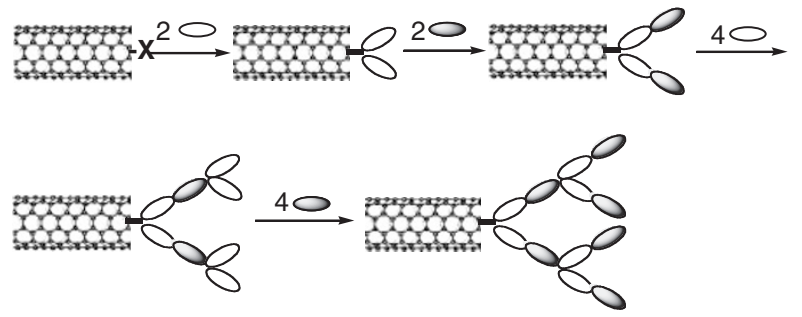

Scheme 1. tion of various monomers initiated by conventional initiators in the presence of CNT and VGCF or by the deactivation of living polymer chain ends with functional groups on these surfaces.

(2) "Polymer reaction" method: polymers are grafted by reactions of surface functional groups on CNT and VGCF with polymers having functional groups, such as hydroxyl, carboxyl, and amino groups. This method can be included for "grafting onto" method.

(3) "Grafting from" method: the initiation of graft polymerization of various monomers from radical and ionic initiating groups previously introduced onto the CNT and VGCF surfaces.

(4) "Stepwise growth" method: grafted polymer chains are grown from the surface functional groups on CNT and VGCF by repeated reaction of low molecular compounds by dendrimer synthesis methodology.

By method (1), although polymer-grafted CNT and VGCF can be readily obtained without pretreatment of the surface, polymer grafting onto the surface (percentage of grafted polymer on CNT and VGCF) is less than $10 \%$, because of the preferential formation of ungrafted polymers. By termination of living polymers on carbon nanofiber, polymers with well-defined molecular weight and narrow molecular weight distribution can be grafted onto CNT and VGCF.

An important characteristic of method (2) is that not only molecular weight and number of grafted chains on CNT and VGCF surfaces are easily controlled, but also commercially available polymers and copolymers having a well-defined structure can be grafted.

Method (3) is best for preparation of polymer-grafted CNT and VGCF with a high percentage of grafting. By initiation of living polymerization from the surface, polymers with well-defined molecular weight and narrow molecular weight distribution can be 
grafted onto these surfaces. Grafting density on the surface is considerably high.

By method (4), hyperbranched polymers having a large number of terminal functional groups can be grafted onto the surface, although polymers with theoretical dendron structure can hardly be grafted.

\section{GRAFTING SITES ON CARABON NANOTUBE AND NANOFIBER}

We reported the grafting of various polymers such as vinyl polymer ${ }^{17,18}$ polyester, ${ }^{19,20}$ polyether, ${ }^{21,22}$ poly(organophosphazene), ${ }^{23}$ and poly(dimethysiloxane $)^{24}$ onto carbon black surface using carboxyl and phenolic hydroxyl groups, bonded at the edges and corners of the polycondensed aromatic ring of graphene sheet or to carbon atoms in defect positions of the graphen sheet, as a grafting site as shown in Figure 2.

However, in comparison with carbon black, the surface grafting of polymers onto graphite powder and carbon fiber surface was rarely achieved, because graphite and carbon fiber have few functional groups as grafting sites. In general, surface grafting onto graphite and carbon fiber must be achieved after the introduction of functional groups using conventional organic reactions, such as oxidation and electrophilic substitution to polycondensed aromatic rings of the surface. The introduction of nitro, hydroxymethyl, and acyl and alkyl groups onto carbon black has been achieved. $^{25,26}$

CNTs have no functional groups and VGCF has few functional groups at the edge (open end) of the fiber. The introduction of functional groups onto $\mathrm{CNT}^{27-32}$ and $\mathrm{VGCF}^{33}$ surface was reported and these functional groups can be used as grafting sites of polymers.

Polycondensed aromatic rings (graphene sheet) of carbon materials, such as carbon black, carbon fiber, and graphite, act as strong radical scavengers. ${ }^{34,35}$

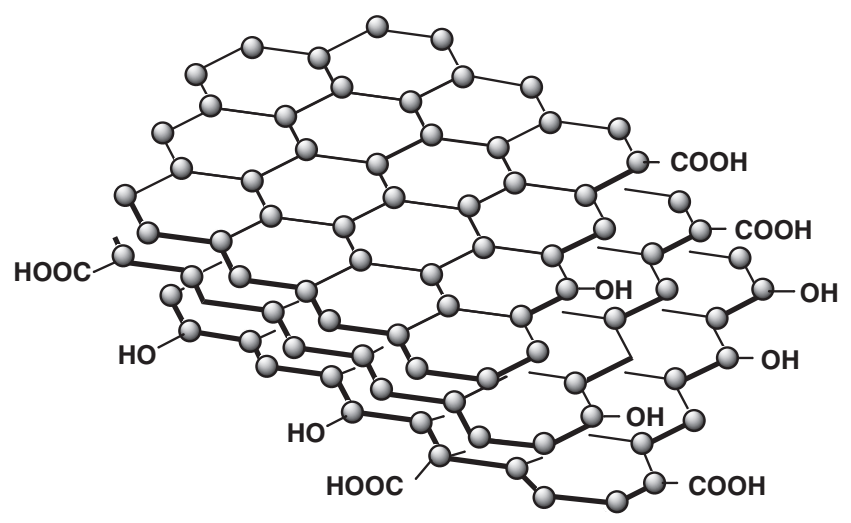

Figure 2. Functional groups of on the edges of graphene sheets of carbon materials.
Therefore, the surface grafting of polymers onto carbon black and graphite can be achieved by the radical trapping nature of these surfaces.

CNTs and VGCF have a strong ability to trap radicals and the grafting of polymers onto the surface can be achieved through polymer radical trapping by these surfaces. Recently, we have found a novel grafting method, which uses the polycondensed aromatic rings (graphene sheet) of carbon black, carbon fiber, ${ }^{36}$ $\mathrm{CNT},{ }^{37}$ and $\mathrm{VGCF}^{38}$ as grafting sites.

\section{GRAFTING OF POLYMERS ONTO CARBON NANOTUBE AND NANOFIBER SURFACES BY LIGAND-EXCHANGE REACTION}

Nesmeyanov et al. reported that the $\eta^{6}$-benzene $\eta^{5}$-cyclopentadienyl-iron(I) cation could be readily prepared by ligand-exchange reaction of ferrocene with benzene in the presence of $\mathrm{AlCl}_{3}$ and aluminum powder ${ }^{39,40}$ and demonstrated that ligand-exchange reaction proceeds with not only benzene but also with other arenes. ${ }^{41-44}$ Miyake et al. reported that ligandexchange reaction of ferrocene can be applied to the introduction of functional groups to graphene sheet of various carbon materials, such as active carbon fiber and carbon black. ${ }^{45}$

\section{Grafting of Poly(Vf-co-MMA) onto CNT and VGCF}

The grafting of poly(vinyl ferrocene-co-methyl methacrylate) (poly(Vf-co-MMA)) onto VGCF surface by ligand-exchange reaction between ferrocene moieties of the copolymer and aromatic rings of graphene sheet of multi-walled carbon nanotube (MWCNT) and VGCF was investigated by our group as shown in Scheme 2. ${ }^{37,38}$

Table I shows the results of grafting reaction of poly $(\mathrm{Vf}-\mathrm{co}-\mathrm{MMA})\left(M_{\mathrm{n}}=1.3 \times 10^{4}, \mathrm{Vf}\right.$ content $=$ $24 \mathrm{~mol} \%$ ) with VGCF surface under several conditions. As shown in Table I, even if VGCF is heated with poly(Vf-co-MMA) in 1,4-dioxane in the absence
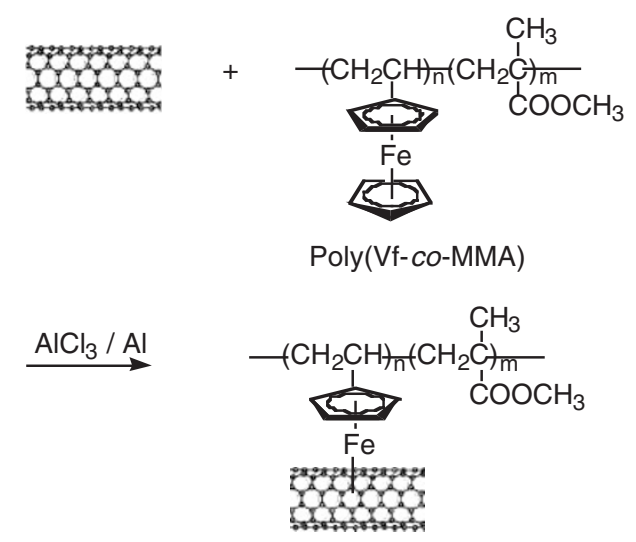

Scheme 2. 
Table I. Ligand-exchange reaction of poly(Vf-co-MMA) with VGCF under various conditions

\begin{tabular}{cccc}
\hline Run No. & $\begin{array}{c}\mathrm{AlCl}_{3} \\
(\mathrm{mmol})\end{array}$ & $\begin{array}{c}\mathrm{Al} \\
(\mathrm{mmol})\end{array}$ & $\begin{array}{c}\text { Grafting } \\
(\%)\end{array}$ \\
\hline 1 & - & - & trace \\
2 & - & 0.25 & 4.3 \\
3 & 1.0 & - & 16.5 \\
4 & 1.0 & 0.25 & 57.5 \\
\hline
\end{tabular}

VGCF, $0.20 \mathrm{~g}$; poly(Vf-co-MMA) $\left(M_{\mathrm{n}}=1.3 \times 10^{4}\right), 0.20 \mathrm{~g}$; 1,4-dioxane, $20.0 \mathrm{~mL} ; 80^{\circ} \mathrm{C} ; 24 \mathrm{~h}$.

of $\mathrm{AlCl}_{3}$ and $\mathrm{Al}$ powder, grafting of the copolymer onto the surface hardly occurs (Run 1). The grafting of the copolymer onto VGCF surface is scarcely observed in the presence of $\mathrm{Al}$ powder alone (Run 2).

The grafting of a copolymer onto VGCF considerably proceeds in the presence of $\mathrm{AlCl}_{3}$ (Run 3). In the presence of $\mathrm{AlCl}_{3}$ and $\mathrm{Al}$ powder, poly $(\mathrm{Vf}-\mathrm{co}$ MMA) is grafted onto side-wall of VGCF. The percentage of grafting onto VGCF reaches $57.5 \%$ after $24 \mathrm{~h}$ at $80^{\circ} \mathrm{C}$. The density of grafted polymer chain on VGCF surface is calculated to be $0.8 / \mathrm{nm}^{2}$.

Figure 3 shows the relationship between reaction time and the percentage of grafting during ligandexchange reaction of VGCF with poly(Vf-co-MMA) at $80^{\circ} \mathrm{C}$. The grafting increased with reaction time, but not after $24 \mathrm{~h}$.

Table II shows the effects of Vf content of poly(Vfco-MMA) on the ligand-exchange reaction with MW$\mathrm{CNT}$ and VGCF. The percentage of grafting and number of grafted chains $\left(G_{\mathrm{n}}\right)$ onto MW-CNT and VGCF increased with Vf content of poly(Vf-co-MMA).

Introduction of Carboxyl Groups onto CNT and VGCF by Ligand-exchange Reaction and Grafting of PEG onto the Surface

The introduction of carboxyl groups onto MWCNT and VGCF surface by ligand-exchange reaction of $1,1^{\prime}$-dicarboxyferrocene $\left(\right.$ Fer- $\left.(\mathrm{COOH})_{2}\right)$ with graphene sheet of these surfaces was investigated as shown in Scheme 3(1). ${ }^{37,38}$

Even in the absence of $\mathrm{AlCl}_{3}$, carboxyl groups are

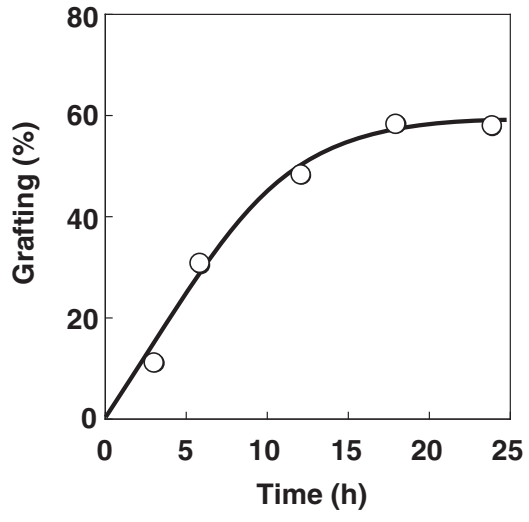

Figure 3. Relationship between reaction time and percentage of grafting in the ligand-exchange reaction of poly(Vf-co-MMA) with VGCF surface at $80^{\circ} \mathrm{C}$. VGCF, $0.20 \mathrm{~g}$; poly(Vf-co-MMA) $\left(M_{\mathrm{n}}=1.3 \times 10^{3}\right), 0.20 \mathrm{~g} ;$ 1,4-dioxane, $20.0 \mathrm{~mL} ; \mathrm{AlCl}_{3}, 1.0 \mathrm{mmol}$; Al powder, $0.25 \mathrm{mmol}$.

Table II. Effects of Vf content on the ligand-exchange reaction of poly(Vf-co-MMA) with MW-CNT and VGCF

\begin{tabular}{lccc}
\hline Nanofiber & $\begin{array}{c}\text { Vf content in the } \\
\text { copolymer }(\mathrm{mol} \%)\end{array}$ & $M_{\mathrm{n}} \times 10^{-4}$ & $\begin{array}{c}\text { Grafting } \\
(\%)\end{array}$ \\
\hline MW-CNT & 9 & 1.5 & 19.6 \\
MW-CNT & 24 & 1.3 & 60.9 \\
VGCF & 1 & 1.9 & 6.4 \\
VGCF & 9 & 1.5 & 24.9 \\
VGCF & 24 & 1.3 & 57.5 \\
VGCF & 47 & 0.6 & 69.3 \\
\hline
\end{tabular}

Carbon nanofiber, $0.20 \mathrm{~g}$; poly(Vf-co-MMA), $0.20 \mathrm{~g}$; 1,4dioxane, $20.0 \mathrm{~mL}$; $\mathrm{AlCl}_{3}, 1.0 \mathrm{mmol}$; $\mathrm{Al}$ powder, $0.25 \mathrm{mmol}$; $80^{\circ} \mathrm{C} ; 24 \mathrm{~h}$.

detected on the VGCF surface by titration. This suggests that Fer- $(\mathrm{COOH})_{2}$ is strongly adsorbed onto VGCF and/or intercalated between graphene sheets of VGCF. Carboxyl group content of VGCF increased when treated with Fer- $(\mathrm{COOH})_{2}$ with VGCF in the presence of $\mathrm{AlCl}_{3}$ and $\mathrm{Al}$ powder. The content of carboxyl group reached to $2.63 \mathrm{mmol} / \mathrm{g}$, but not after $24 \mathrm{~h}$. This indicates that carboxyl group density on VGCF wall-surface is $100 / \mathrm{nm}^{2}$. The amount of

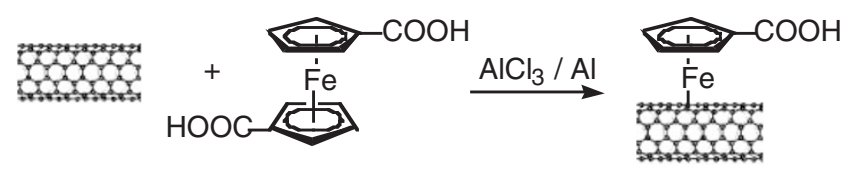

Fer- $(\mathrm{COOH})_{2}$

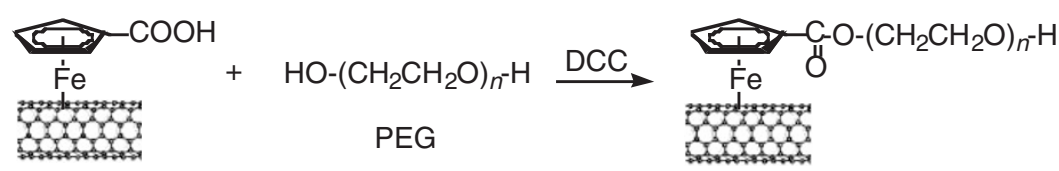

Scheme 3. 
Table III. Grafting reaction of MW-CNT-COOK and VGCF-COOH with PEG in the presence of DCC

\begin{tabular}{lccc}
\hline \multicolumn{1}{c}{ Nanofiber } & $M_{\mathrm{n}} \times 10^{-3}$ & $\begin{array}{c}\text { Grafting } \\
(\%)\end{array}$ & $\begin{array}{c}G_{\mathrm{n}} \times 10^{-18} \\
(\mathrm{No} . / \mathrm{g})\end{array}$ \\
\hline MW-CNT-COOH & 4.6 & 57.5 & 36.7 \\
MW-CNT-COOH & 3.4 & 24.6 & 43.3 \\
MW-CNT-COOH & 2.0 & 19.0 & 57.2 \\
VGCF-COOH & 10.0 & 14.7 & 9.9 \\
VGCF-COOH & 8.0 & 12.4 & 9.3 \\
VGCF-COOH & 4.6 & 8.9 & 11.6 \\
VGCF-COOH & 3.4 & 11.0 & 19.5 \\
VGCF-COOH & 2.0 & 9.6 & 28.9 \\
VGCF-COOH & 1.5 & 8.8 & 35.3 \\
\hline
\end{tabular}

Carbon nanofiber-COOH, $0.10 \mathrm{~g}$; PEG, $0.53 \mathrm{mmol}$; THF, $20.0 \mathrm{~mL}$; DCC, $0.26 \mathrm{mmol} ; 60^{\circ} \mathrm{C} ; 48 \mathrm{~h}$.

carboxyl group introduced onto VGCF surface was extremely large in comparison with that introduced by the oxidation of open ends of VGCF with nitric acid. ${ }^{46,47}$ Carboxyl groups were introduced onto MW-CNT surface by ligand-exchange reaction with Fer- $(\mathrm{COOH})_{2}$. The amount of carboxyl groups was determined to be $4.30 \mathrm{mmol} / \mathrm{g}$, indicating $3 / \mathrm{nm}^{2}$ density of carboxyl groups.

It is expected that the grafting of PEG onto MWCNT-COOH and VGCF-COOH by direct condensation of carboxyl groups on the surfaces with terminal hydroxyl groups of poly(ethylene glycol) (PEG) proceeds in the presence of a condensing agent as shown in Scheme 3(2). ${ }^{37,38}$

By reaction of MW-CNT-COOH and VGCF$\mathrm{COOH}$ with PEG $\left(M_{\mathrm{n}}=3.4 \times 10^{3}\right)$ in the presence of $N, N^{\prime}$-dicyclohexylcarbodiimide (DCC), PEG was grafted onto MW-CNT and VGCF surface. The percentage of grafting onto MW-CNT and VGCF reached $24.6 \%$ and $11.0 \%$, respectively, for $48 \mathrm{~h}$ at $60^{\circ} \mathrm{C}$, but not after $48 \mathrm{~h}$. This indicates that only $1-$ $1.7 \%$ of carboxyl groups are used for the grafting site.

PEG is thus grafted onto MW-CNT and VGCF surface with ester bonds by reaction of carboxyl groups on side-wall of MW-CNT and VGCF with terminal hydroxyl groups of PEG in the presence of DCC.

Table III shows the effect of molecular weight of PEG on the grafting onto MW-CNT-COOH and VGCF-COOH. The percentage of grafting tends to decrease with decreasing molecular weight of PEG, but the number of grafted PEG chains $\left(G_{\mathrm{n}}\right)$ on the surface increased with decreasing molecular weight of PEG. This suggests that steric hindrance decreased with decreasing molecular weight of PEG. The same was reported in the grafting reaction of functional groups on nano-sized particle surface with polymers having terminal functional groups. ${ }^{48,49}$

Grafting of polymers having hydroxyl and amino (imino) groups, such as polyethylene-block-poly(ethy-
Table IV. Grafting reaction of VGCF-COOH with several polymers in the presence of DCC

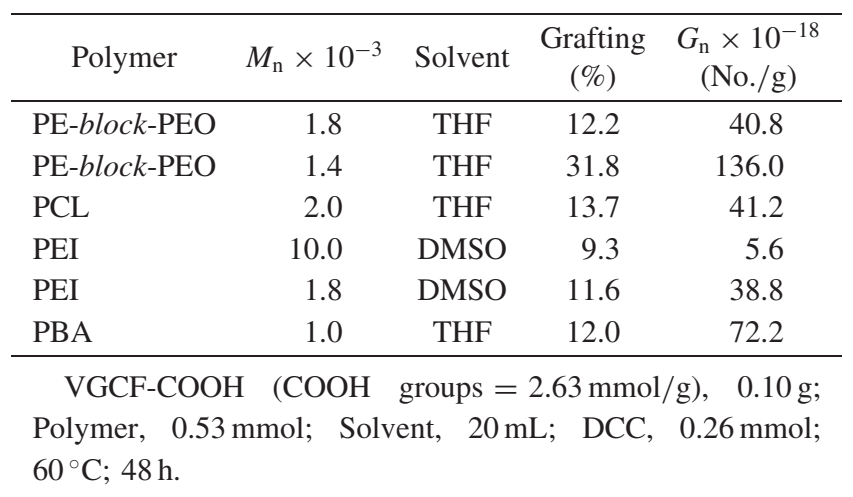

lene oxide) (PE- $b$-PEO), poly( $\varepsilon$-caprolactone) (PCL), poly(ethyleneimine) (PEI), and poly(butyleneadipate) (PBA), onto VGCF-COOH was investigated. The results are shown in Table IV. These polymers, such as PE- $b$-PEG, PCL, PEI and PBA, were grafted onto VGCF surface by the direct condensation of terminal functional groups of polymers with carboxyl groups on VGCF in the presence of DCC. . $^{37,38}$

\section{GRAFTING OF POLYMERS ONTO CARBON NANOTUBE AND NANOFIBER BY RADICAL TRAPPING}

Carbon black is a strong radical scavenger. ${ }^{34,35}$ Therefore, the radical polymerization in the presence of carbon black was inhibited and/or retarded, because of the trapping of growing polymer radicals and primary radicals by carbon black surface. During polymerization, a part of the polymer was grafted onto the surface, but the percentage of grafting was less than a few percent, because of preferential trapping of low molecular primary radicals formed by the decomposition of initiator. ${ }^{50,51}$

Our group has reported that polymer radicals formed by the thermal decomposition of macroinitiators, polymers having azo group ${ }^{52}$ and peroxy groups, ${ }^{53}$ are trapped by polycondensed aromatic rings of the surface to give the corresponding polymergrafted carbon black and graphite.

Grafting onto CNT by Trapping of Polymer Radicals Formed by the Thermal Decomposition Macro-azo Initiator

To confirm the radical trapping nature of MW-CNT and cup-stacked CNT (CS-CNT), the effects of these CNTs on the radical polymerization of styrene initiated by benzoyl peroxide (BPO) was investigated. The results are shown in Figure 4. As shown in Figure 4, in the presence of MW-CNT and CS-CNT, radical polymerization of styrene was retarded. During radical polymerization, a part of polystyrene formed was 


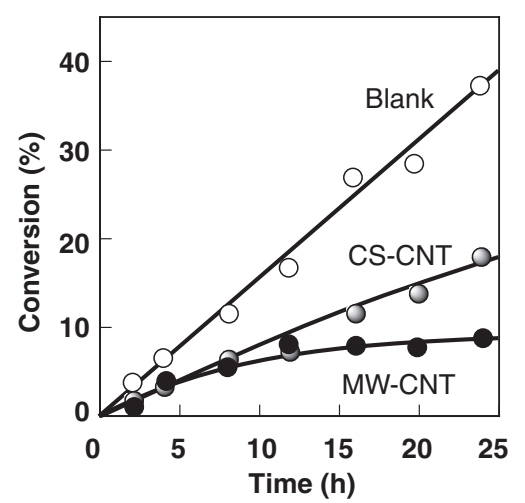

Figure 4. Radical polymerization of styrene in the presence of MW-CNT and CS-CNT initiated by BPO. CNT, $0.10 \mathrm{~g}$; styrene, $10.0 \mathrm{~mL}$; BPO, $0.10 \mathrm{~g} ; 60^{\circ} \mathrm{C}$.

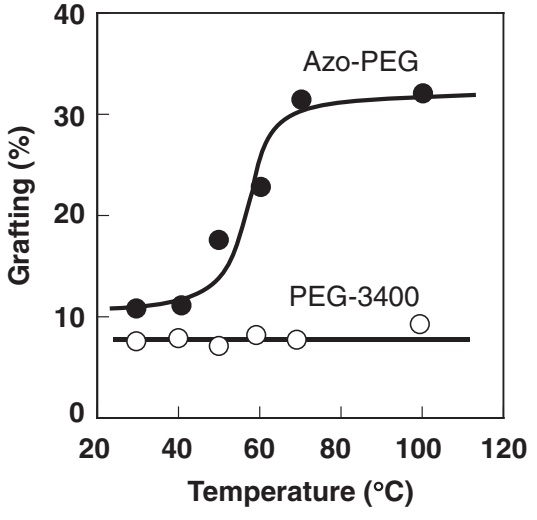

Figure 5. Effects of temperature on the reaction of Azo-PEG with MW-CNT and CS-CNT. CNT, $0.07 \mathrm{~g}$; Azo-PEG (PEG), $2.5 \mathrm{~g}$; toluene, $20.0 \mathrm{~mL} ; 24 \mathrm{~h}$.

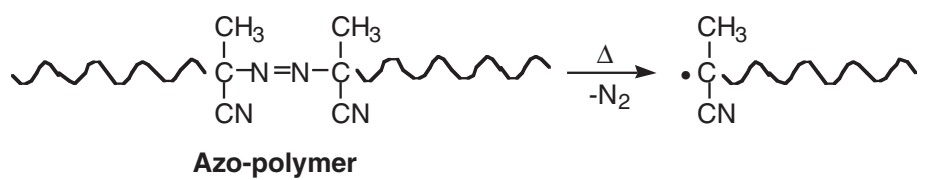

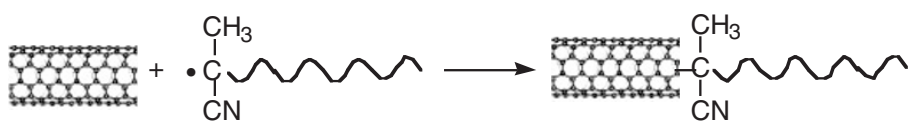

Scheme 4.

grafted onto the surface of MW-CNT and CS-CNT, but the percentage of grafting was less than a few percent. This indicates that primary radicals, benzoyloxy radicals, may be preferentially trapped by MW-CNT and CS-CNT surfaces.

Polymer radicals formed by the decomposition of macro-initiators, such as azo-polymer, should thus be trapped by MW-CNT and CS-CNT surfaces. MW-CNT was reacted with PEG-azo initiator, AzoPEG, in toluene and the results are shown in Figure 5. Even when PEG having no azo groups was heated with MW-CNT, no grafting of PEG onto the MWCNT surface was observed. When Azo-PEG was reacted with MW-CNT below $40^{\circ} \mathrm{C}$, at which AzoPEG scarcely decomposed, no grafting was observed. Grafting proceeded when MW-CNT was reacted above $60{ }^{\circ} \mathrm{C}$, at which the thermal decomposition of Azo-PEG proceeds. The percentage of grafting onto MW-CNT reached to $31.0 \%$ at $70^{\circ} \mathrm{C}$ after $24 \mathrm{~h}$. The grafting of PEG onto CS-CNT also proceeded by reaction with Azo-PEG. The percentage of PEG grafting was determined to be $11.8 \%$ at the same conditions.

These results indicate that at above $60^{\circ} \mathrm{C}$, PEG radicals formed by the thermal decomposition of Azo-PEG are trapped by the surface of MW-CNT and CS-CNT to give PEG-grafted CNTs as shown in Scheme $4 .{ }^{37}$
It is interesting to note that the percentage of grafting onto MW-CNT was higher than that onto CSCNT, although CS-CNT has more open ends (edges) as radical trapping sites than MW-CNT. This may be due to the fact that the open ends of CS-CNT were readily shielded by grafted PEG chains.

\section{Grafting onto CNT by Trapping of Living Polymer Radical}

Lou and his coworkers reported the grafting of polymers onto MW-CNT by the trapping of living polymer radicals formed by the thermal dissociation of alkoxyamine, 2,2,6,6-tertamethylpiperidinyl-1-oxyl (TEMPO), end-capped polymers, such as polystyrene (PS) and poly ( $\varepsilon$-caprolactone) (PCL), and their block copolymers (PCL- $b$-PS), as shown in Scheme 5. ${ }^{54}$

As shown in Table V, by the grafting methods, polymers with controlled molecular weight and narrow molecular weight distribution were grafted onto MW-CNT. It is also reported that the grafting density $(\mathrm{mol} / \mathrm{mg})$ decreases with increasing molecular weight of TEMPO-terminated polystyrene. ${ }^{54}$

Poly(2-vinylpyridine) was grafted onto MW-CNT by trapping of polymer radicals formed by the decomposition of the corresponding TEMPO end-capped polymers. ${ }^{55}$ The polymer-grafted MW-CNT gave a stable dispersion in acidic water, but precipitated in 

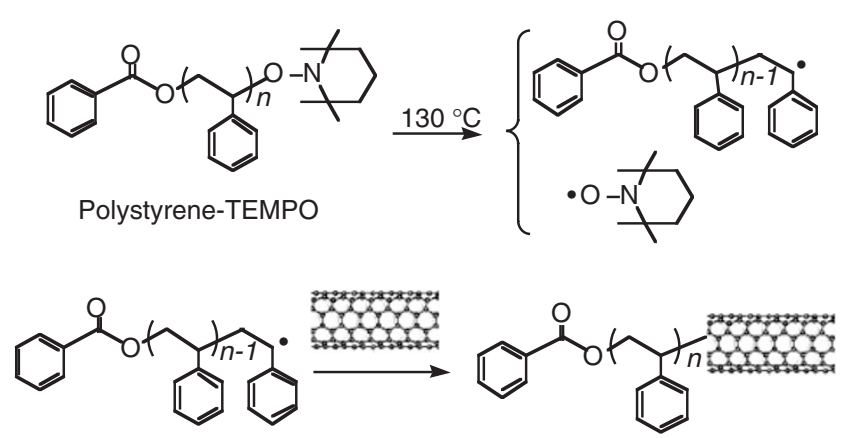

Scheme 5.

Table V. Grafting of TEMPO-terminated polymers onto MW-CNT

\begin{tabular}{lrccc}
\hline \multicolumn{1}{c}{ Polymer } & $M_{\mathrm{n}} \times 10^{3}$ & $M_{\mathrm{w}} / M_{\mathrm{n}}$ & $\begin{array}{c}\text { Time } \\
(\mathrm{h})\end{array}$ & $\begin{array}{c}\text { Grafting } \\
(\%)\end{array}$ \\
\hline PS-TEMPO & 3.0 & 1.20 & 24 & 12 \\
PS-TEMPO & 3.0 & 1.20 & 43 & 12.5 \\
PS-TEMPO & 17.5 & 1.25 & 24 & 20 \\
PS-TEMPO & 19.5 & 1.20 & 24 & 17 \\
PS-TEMPO & 28.5 & 1.25 & 24 & 24 \\
PCL-TEMPO & 7.0 & 1.20 & 24 & 25 \\
PCL-TEMPO & 14.5 & 1.15 & 24 & 28 \\
(PCL-co-PS)-TEMPO & 15.5 & 1.20 & 24 & 30 \\
\hline
\end{tabular}

MW-CNT, $0.02 \mathrm{~g}$; polymer, $2.0 \mathrm{~g}$; toluene, $6 \mathrm{~mL} ; 130^{\circ} \mathrm{C}$.

alkaline water. Datsyuk et al. reported the preparation of composite from double-walled CNT and polymer via in-situ niroxide mediated polymerization of amphiphilic block copolymers, although the grafting of the block copolymer was not been clarified. They used 2-methyl-2- $N$-tert-butyl- $N$-[diethoxyphoshoryl-2,2dimethypropylaminoxy] propionic acid as niroxide. ${ }^{56}$

\section{Grafting onto VGCF by Trapping of Polymer Radicals Formed by $\gamma$-Ray Irradiation}

The $\gamma$-ray radiation grafting of polymers by trapping of polymer radicals formed by the $\gamma$-ray irradiation has been reported by our group. The grafting of PE- $b$-PEO onto VGCF surface was carried out in a solvent-free system. That is, the PE- $b$-PEO was pre-adsorbed onto VGCF surface from PE- $b$-PEO solution of THF; then, the PE- $b$-PEO-adsorbed VGCF was irradiated at the definite dose and temperature (Scheme 6) ${ }^{57}$

Figure 6 shows the relationship between the percentage of grafting and irradiation dose at 25, 50, 75,100 , and $110^{\circ} \mathrm{C}$. The irradiation dose rate was fixed to $10 \mathrm{kGy} / \mathrm{h}$. The points at the 0 (dose axial) indicate that the samples are only heated at the corresponding temperatures for $6 \mathrm{~h}$. As shown in Figure 6, grafting reaction is remarkably affected by irradiation temperature. At lower irradiation temperatures of 25, 50 , and $75^{\circ} \mathrm{C}$, the grafting was less than $5.0 \%$. At $100{ }^{\circ} \mathrm{C}$, the grafting at $60 \mathrm{kGy}$ dose reached $7.3 \%$,

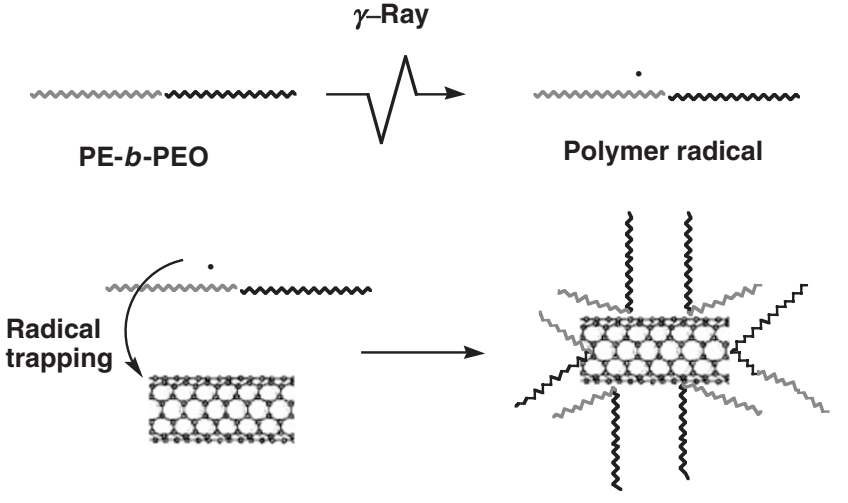

Scheme 6.

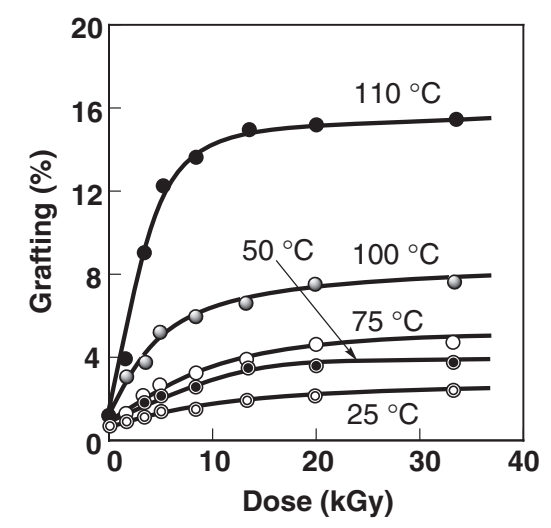

Figure 6. Relationship between percentage of PE- $b$-PEO grafting and irradiation dose of the radiation grafting of PE- $b$ PEO onto VGCF at various temperatures. The amount of adsorbed PE- $b$-PEO on VGCF before irradiation was $74 \%$ (weight percent of PE- $b$-PEO on VGCF).

and at $110^{\circ} \mathrm{C}$, near the melting point $\left(109^{\circ} \mathrm{C}\right)$ of PE- $b$-PEO, the grafting suddenly increased to $15.0 \%$.

Grafting increased with irradiation dose at every irradiation temperature. Without irradiation, the grafting of PE- $b$-PEO on the VGCF was less than $1.0 \%$. At lower irradiation temperatures, such as $25^{\circ} \mathrm{C}$, even if the radiation dose increased to $100 \mathrm{kGy}$, the percentage of PE- $b$-PEO grafting was less than $2.3 \%$. This may be due to the fact that PE- $b$-PEO radicals hardly reacted with the VGCF surface because of the crystalline structure of PE- $b$-PEO.

The grafting of PE- $b$-PEO onto VGCF surface is considered to proceed through the trapping of PE- $b$ PEO radical by the graphene sheet of the VGCF. ${ }^{57}$ Compared with the rate of PE- $b$-PEO radical generation in the above irradiation dose rate, the rate of radical trapping by VGCF was relatively slow. Therefore, at higher irradiation dose rate, some PE- $b$-PEO radical is quenched before the grafting reaction, resulting in no increase of PE- $b$-PEO grafting.

Crosslinked PE- $b$-PEO formed by irradiation is unable to be removed by Soxhlet extraction with 

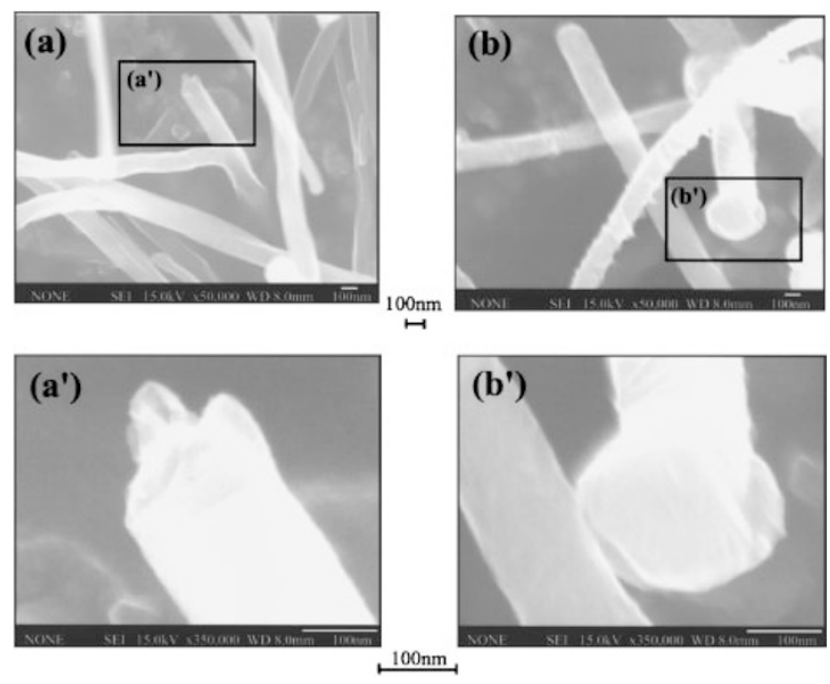

Figure 7. FE-SEM aspects of $\left(a, a^{\prime}\right)$ untreated VGCF and $\left(\mathrm{b}, \mathrm{b}^{\prime}\right)$ PE- $b$-PEO-grafted VGCF.

THF. However, for the $\gamma$-ray irradiated PE- $b$-PEO in the absence of VGCF, crosslinking of PE- $b$-PEO was less than $7.3 \%$ even if irradiated under $60 \mathrm{kGy}$. FE-SEM observation indicated that all of polymer covered the VGCF surface. Therefore, the grafting of PE- $b$-PEO onto the VGCF surface through the trapping of PE- $b$-PEO radical is considered as the main reaction under the above condition.

Field-emission scanning electron microscope (FESEM) was used to monitor changes in surface structure induced by the grafting of PE- $b$-PEO on VGCF. FESEM imagines of original VGCF are shown in Figure $7 \mathrm{a}$ and $\mathrm{a}^{\prime}$, and those of PE- $b$-PEO-grafted VGCF, grafting $=15.0 \%$ in Figure $7 b$ and $b^{\prime}$. As shown in Figure $7 \mathrm{a}$ and $\mathrm{a}^{\prime}$, the diameter of the original VGCF was about $100 \mathrm{~nm}$, and the surface was very clean and smooth. However, the end of the VGCF was not smooth and annular carbon layers could be seen.

The surface of PE- $b$-PEO-grafted VGCF shown in Figure $7 b$ and $b^{\prime}$ was rough in comparison with the original one. This may be due to the fact that a layer of grafted PE- $b$-PEO covered on VGCF uniformly. The end of the VGCF has more grafted by PE- $b$-PEO.

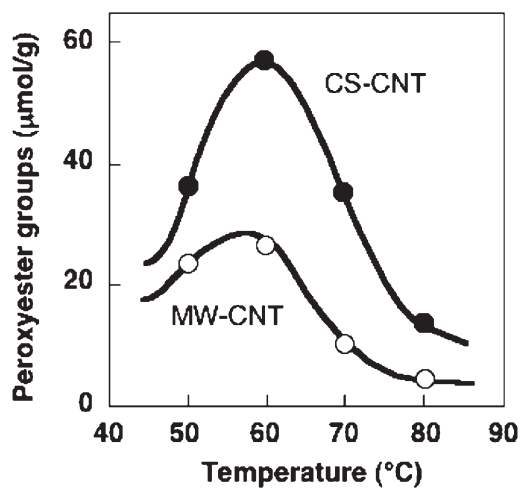

Figure 8. Effects of temperature on the introduction of peroxyester groups onto MW-CNT and CS-CNT by the reaction with BDOC. CNT, $0.02 \mathrm{~g}$; BDOC, $10.0 \mathrm{~mL}$; hexane, $10.0 \mathrm{~mL}$.

Therefore, it could be concluded that the PE- $b$-PEO is grafted onto the VGCF surface, and the grafting of polymer to end of VGCF readily proceeds. There was no distinct difference in the diameter before and after PE- $b$-PEO grafting. Because the grafted layer on the VGCF surface was too thin. The thickness of PE- $b$ PEO grafted layer from the weight of grafted PE- $b$ PEO is only about $10 \mathrm{~nm}$.

\section{Introduction of Peroxyester Groups onto CNT by Rad- ical Trapping}

1,1-Bis(t-butyldioxy)cyclohexane (BDOC) thermally decomposes near $70^{\circ} \mathrm{C}$ to give radicals having peroxyester groups and $t$-butoxy radical [Scheme $7(1)] .{ }^{58} \mathrm{We}$ introduced peroxyester groups onto carbon black surface by the trapping of the radicals having peroxyester moiety and the radical graft polymerization of vinyl monomers initiated by the peroxyester groups on the surface. ${ }^{59}$ Therefore, the introduction of peroxyester groups onto MW-CNT and CS-CNT by the treatment with BDOC was examined in hexane as shown in Scheme 7(1). ${ }^{37}$

The results are shown in Figure 8. Peroxyester groups are readily introduced onto MW-CNT and CS-CNT surfaces. Peroxyester groups on the surface increased with reaction temperature, but decreased

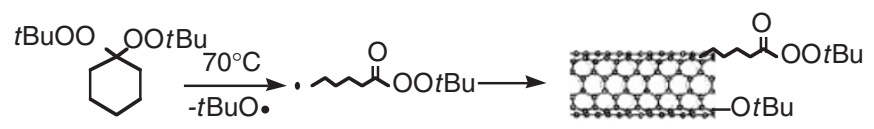

BDOC
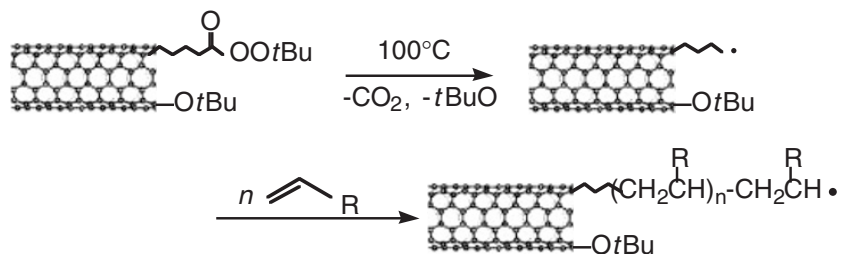

Scheme 7. 
Table VI. Introduction of peroxyester groups onto MW-CNT by the reaction with BDOC in hexane and solvent RTIL

\begin{tabular}{lrc}
\hline Solvent & $\begin{array}{c}\text { Time } \\
(\mathrm{h})\end{array}$ & $\begin{array}{c}\text { Peroxyester groups } \\
(\mu \mathrm{mol} / \mathrm{g})\end{array}$ \\
\hline RTIL & 8 & 30.1 \\
RTIL & 10 & 34.9 \\
RTIL & 12 & 38.3 \\
Hexane & 10 & 9.5 \\
\hline
\end{tabular}

MW-CNT, $0.02 \mathrm{~g}$; BDOC, $10.0 \mathrm{~mL}$; solvent, $10 \mathrm{~mL} ; 70^{\circ} \mathrm{C}$.

above $60^{\circ} \mathrm{C}$. This indicates that the thermal decomposition of peroxyester groups on the surface proceeds with increasing reaction temperature. The amount of peroxyester groups introduced onto CS-CNT was larger than that onto MW-CNT. This may be due to the fact that the edge of CS-CNT traps low molecular weight radicals more than MW-CNT, different from polymer radicals with large molecular weight.

The effect of 1-butyl-3-methylimidazolium hexafluorophosphate (RTIL) as reaction solvent on the trapping of radicals by CNTs was investigated. The results are shown in Table VI. The amount of peroxyester groups introduced onto MW-CNT by the reaction with BDOC in RTIL was much larger than that in hexane, because of the stabilization of free radicals in RTIL. ${ }^{60}$

\section{RADICAL GRAFTING OF POLYMERS FROM CARBON NANOTUBE AND NANOFIBER SURFACES}

\section{The Radical Graft Polymerization from Peroxyester Groups on CNT}

The radical graft polymerization of vinyl monomers initiated by MW-CNT and CS-CNT having peroxyester groups was carried out as shown in Scheme $7(2) .{ }^{37,60}$ Radical graft polymerizations of vinyl monomers were initiated by peroxyester groups introduced onto the MW-CNT and CS-CNT surfaces at $100^{\circ} \mathrm{C}$ to give the corresponding vinyl polymer grafted MWCNT and CS-CNT. The percentage of grafting of poly(methyl methacrylate) (poly(MMA)) onto MWCNT in hexane and RTIL reached to 6.6 and $60.2 \%$, respectively. Polymer-grafted CNT with considerably higher grafting can be obtained in RTIL, because of stabilization of free radicals in RTIL. ${ }^{60}$

Radical Grafting of Polymers from CNT Surface by Atom Transfer Radical Polymerization

Kong et al. reported the grafting of polyMMA from MW-CNT via atom transfer radical polymerization (ATRP) by three steps as shown in Scheme $8 ;{ }^{61}$ (1) introduction of acyl chloride groups onto MW-CNT by the reaction of carboxyl groups with thonyl chloride, (2) introduction of initiating sites for ATRP,
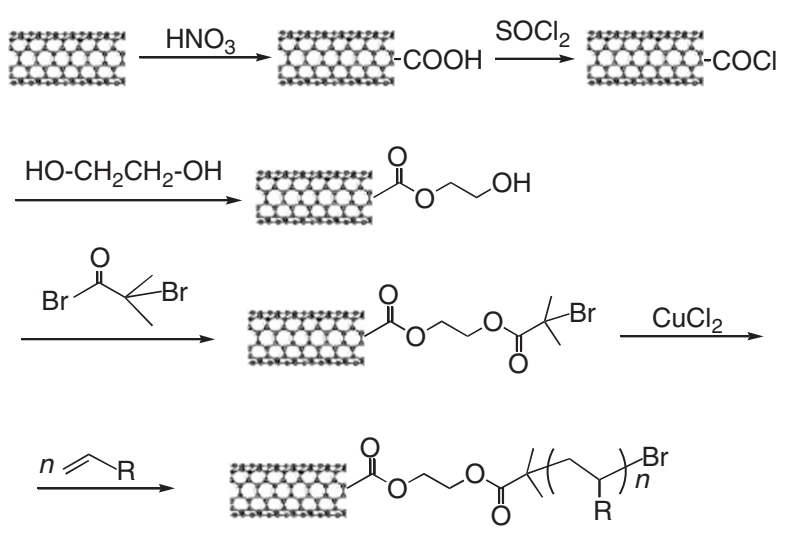

Scheme 8.

2-bromo-2-methylpropionate groups, onto MW-CNT by the reaction of acyl chloride groups with ethylene glycol followed by the treatment with 2-methyl-2bromopropionyl bromide, and (3) graft polymerization of MMA from the bromopropionate groups in the presence of $\mathrm{CuBr} / N, N, N^{\prime}, N^{\prime}, N^{\prime}$-pentamethyldiethylenediamine by in-situ ATRP. The thickness of the polymer layer in the graft polymerization can be well controlled by the feed ratio of MMA to MWCNT having 2-bromo-2-methylpropionate groups.

Quin et al. reported the grafting of $n$-butyl methacrylate ( $n$ BMA) and polystyrene onto SW-CNT by ATRP system consisting of 2-bromopropionate groups on SW-CNT and CuBr/bipyridyl. ${ }^{62,63}$ The initiators of ATRP were covalently attached to SW-CNT by esterification of 2-hydroxymethyl-2'-bromopropionate with acyl chloride groups on the surface. Methyl 2-bromopropionate (MBP) was added as free initiator during the graft polymerization from SW-CNT surface to control growth of grafted chains and monitor the polymerization kinetics.

Figure 9 shows the relationship between conversion and $M_{\mathrm{n}}$ (number average molecular weight) and $M_{\mathrm{w}} / M_{\mathrm{n}}$ (molecular weight distribution) of polystyrene in the grafting of polystyrene onto SW-CNT by the ATRP. ${ }^{63}$ The molecular weight linearly increased with monomer conversion and the molecular weight distribution of free polymer was relatively low. Thus the number of grafting sites on SW-CNT is almost constant during the course of polymerization; i.e., the growth of polystyrene from SW-CNT is controlled.

Radical Grafting of Polymers from VGCF Initiated by the System Consisting of Trichloroacethyl Groups and $\mathrm{Mo}(\mathrm{CO})_{6}$

Bamford et al. reported a system consisting of haloalkyl compounds and transition metal carbonyl derivatives, such as $\mathrm{Mo}(\mathrm{CO})_{6}$ and $\mathrm{Mn}_{2}(\mathrm{CO})_{10}$, to initiate radical polymerization of vinyl monomers. ${ }^{64-67}$ The radical graft polymerization of vinyl monomers 


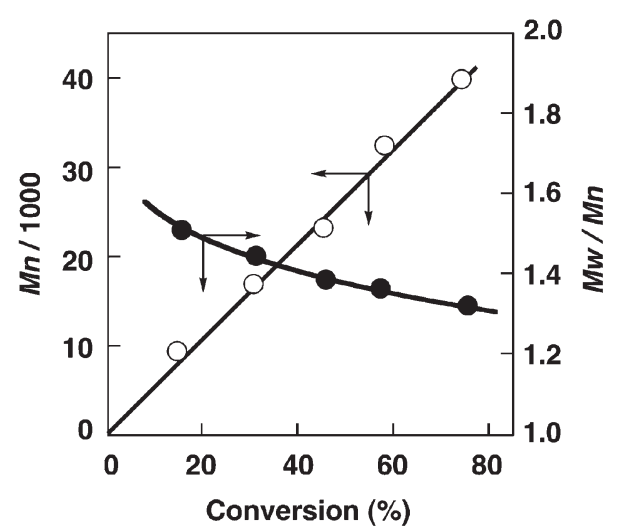

Figure 9. Relationship between conversion and $M_{\mathrm{n}}\left(M_{\mathrm{w}} / M_{\mathrm{n}}\right)$ of polystyrene in the grafting of polystyrene onto SW-CNT by the ATRP. [St]:[initiator]:[CuBr]:[Bipy] $=500: 1: 1: 2$ in dichlororbenzene at $110^{\circ} \mathrm{C}$. Initiator $=\mathrm{SW}$-CNT-initiator $+\mathrm{MBP}$ with $[\mathrm{SW}-\mathrm{CNT}$-initiator $] /[\mathrm{MBP}]=1 / 20$.
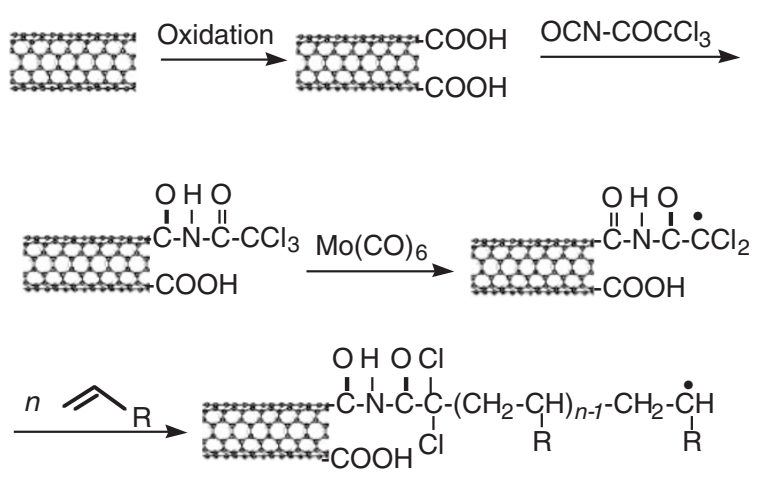

Scheme 9.

initiated by the system consisting of carbon black and nano-sized silica having trichloroacetyl groups and $\mathrm{Mo}(\mathrm{CO})_{6}$ was reported by our group. ${ }^{68,69}$

Therefore, the polymerization of styrene initiated by the system consisting of VGCF-R-COCCl 3 and $\mathrm{Mo}(\mathrm{CO})_{6}$ was investigated as shown in Scheme 9. ${ }^{47}$ The introduction of trichloroacetyl groups onto the surface was achieved by reaction of surface carboxyl and phenolic hydroxyl groups with trichloroacetyl isocyanate.

Figure 10 shows the time-percentage of grafting curves for MMA and styrene initiated by the system consisting of VGCF-R-COCCl${ }_{3}$ and $\mathrm{Mo}(\mathrm{CO})_{6}$ at $100^{\circ} \mathrm{C}$. The percentage of grafting increased with polymerization and percentage of polyMMA and polystyrene grafting exceeded $40 \%$ and $25 \%$, respectively, after $6 \mathrm{~h}$. The system consisting of untreated VGCF and $\mathrm{Mo}(\mathrm{CO})_{6}$ was unable to initiate the polymerization. The graft polymerization of vinyl monomers, such as vinyl acetate and glycidyl methacrylate, onto VGCF was initiated by a system consisting of VGCF-R-COCCl 33 and $\mathrm{Mo}(\mathrm{CO})_{6}$ to give the corresponding polymer-grafted VGCF. ${ }^{47}$

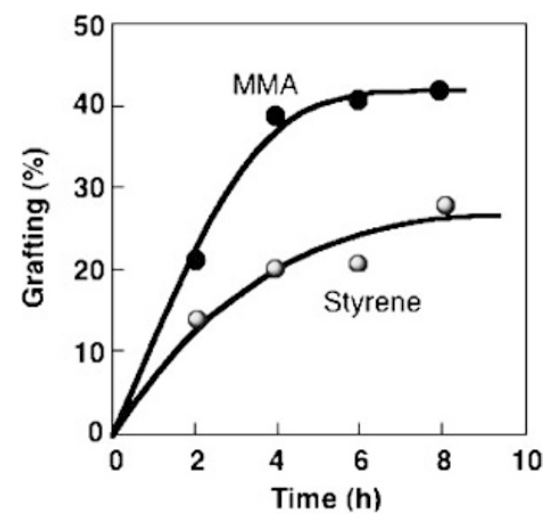

Figure 10. Graft polymerization of MMA and styrene initiated by the system consisting of VGCF-R-COCCl ${ }_{3}$ and $\mathrm{Mo}(\mathrm{CO})_{6}$ at $100{ }^{\circ} \mathrm{C}$. VGCF-R-COCCl${ }_{3}, 0.10 \mathrm{~g} ; \mathrm{Mo}(\mathrm{CO})_{6}, 0.02 \mathrm{~g}$; monomer, $10.0 \mathrm{~mL}$.

These results indicate that the radical polymerization is initiated by surface radicals formed by the reaction of trichloroacetyl groups on VGCF surface with $\mathrm{Mo}(\mathrm{CO})_{6}$ and grafted polymer chains are propagated form the surface as shown in Scheme 9.

Grafting of Polymer onto CNT in-situ Radical Polymerization in the Presence of Radical Initiator

Park et al. reported the grafting of polyMMA onto MW-CNT by in-situ radical polymerization by use of $2,2^{\prime}$-azobisisobutyronitrile (AIBN) as an initiator. The molecular weight of polyMMA increased with MWCNT content. During the polymerization, MW-CNT was shown to be consumed AIBN by opening $\pi$-bonds on MW-CNT surfaces to make radicals and the radical initiate the radical graft polymerization from the surface. ${ }^{70}$ FT-IR spectra for the supporting the generation of new $\pi$-bonds between MW-CNT and polyMMA were shown.

\section{GRAFTING OF POLYMERS FROM CARBON NANOTUBE AND NANOFIBER BY ANIONIC AND COORDINATION POLYMERIZATION}

\section{Grafting of Polymers onto CNT by the Reaction with Polymeric Carbanions}

$\mathrm{Wu}$ et al. reported the grafting of poly( $N$-vinylcarbazole) (polyNVC) and poly(butadiene) onto SWCNT by nuclerophilic reaction of polymeric carbanions generated from organometallic reagents such as sodium hydride or butyllithium. ${ }^{71}$ This method is effective for functionalization of $\mathrm{C}_{60}$ fullerenes. The photoinduced electron transfer was observed in the polyNVC-grafted SW-CNT systems to give large optical limiting effects. ${ }^{71}$

Viswanathan et al. reported the one-step in-situ synthesis of polystyrene-grafted SW-CNT composite. ${ }^{72}$ Carbanions are introduced onto the SW-CNT 

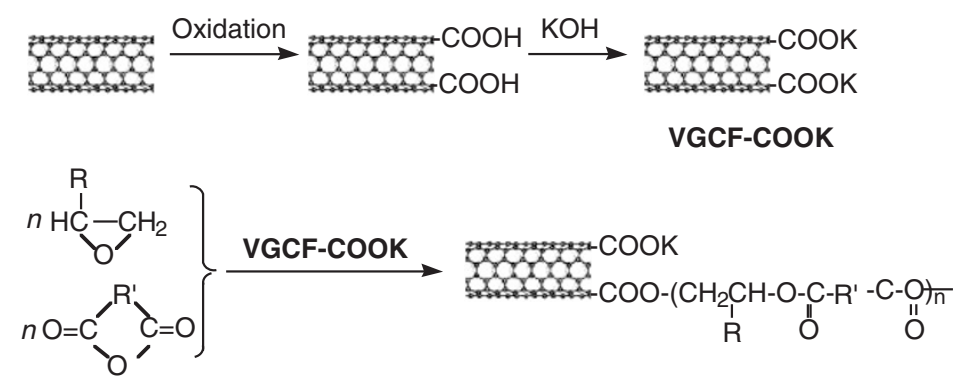

Scheme 10.

Table VII. Anionic ring-opening alternating copolymerization of SO with PAn initiated by COOK groups on VGCF

\begin{tabular}{lcccc}
\hline \multicolumn{1}{c}{ VGCF } & $\begin{array}{c}\text { SO } \\
(\mathrm{mol})\end{array}$ & $\begin{array}{c}\text { PAn } \\
(\mathrm{mol})\end{array}$ & $\begin{array}{c}\text { Conversion } \\
(\%)\end{array}$ & $\begin{array}{c}\text { Grafting } \\
(\%)\end{array}$ \\
\hline Untreated & 0.01 & 0.01 & 0 & - \\
VGCF-COOH & 0.01 & 0.01 & 0 & 0 \\
VGCF-COOK & 0.01 & - & 0 & 0 \\
VGCF-COOK & - & 0.01 & 0 & 0 \\
VGCF-COOK & 0.01 & 0.01 & 9.2 & 4.8 \\
\hline
\end{tabular}

VGCF, $0.10 \mathrm{~g} ; 18$-croown- $6,0.02 \mathrm{~g} ; 120^{\circ} \mathrm{C} ; 8 \mathrm{~h}$.

surface by treatment of anionic initiator that serves to exfoliate bundles and provide initiating sites for the anionic polymerization of styrene.

Grafting of Polyesters onto VGCF by Surface Initiated Anionic Ring-opening Alternating Copolymerization of Epoxides and Cyclic Acid Anhydrides

We reported the anionic ring-opening alternating copolymerization of epoxides with cyclic acid anhydrides is initiated by COOK groups on carbon black surface to give the corresponding polyester-grafted carbon black. ${ }^{73-75}$ Therefore, the ability of VGCF having COOK groups to initiate the anionic ring-opening alternating copolymerization of styrene oxide (SO) with phthalic anhydride (PAn) was investigated as shown in Scheme 10. ${ }^{46}$

The introduction of COOK groups onto VGCF surface was readily achieved by the neutralization of carboxyl groups on VGCF. The results are shown in Table VII. The polymerization was carried out in the presence of crown ether to accelerate the polymerization. ${ }^{75}$ As shown in Table VII, no polymerization of $\mathrm{SO}$ with PAn was initiated in the presence of untreated VGCF and VGCF-COOH. VGCF-COOK didn't initiate the polymerization of $\mathrm{SO}$ and PAn alone. The anionic ring-opening alternating copolymerization of SO with PAn was initiated by VGCF-COOK to give the corresponding polyester-grafted VGCF.

The anionic ring-opening alternating copolymerization of several epoxides with cyclic acid anhydrides

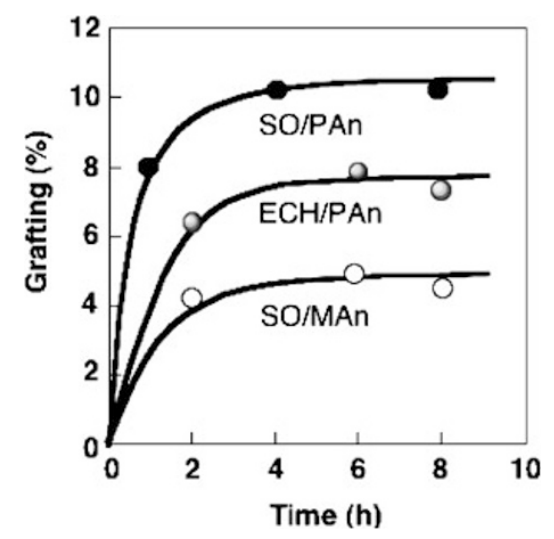

Figure 11. Grafting of polyesters onto VGCF by anionic ringopening alternating copolymerization of epoxides with cyclic acid anhydrides initiated by COOK groups on the surface. VGCF, $0.10 \mathrm{~g}$; epoxide $=$ cyclic acid anhydride $=0.01 \mathrm{~mol} ; 18$-crown$6,0.02 \mathrm{~g} ; 120^{\circ} \mathrm{C}$.

was investigated. Epoxides used were SO and epichlorohydrin $(\mathrm{ECH})$, and cyclic acid anhydrides were PAn and maleic anhydride (MAn). The results are shown in Figure 11. VGCF having COOK groups initiated the anionic ring-opening alternating copolymerization of epoxides with cyclic acid anhydrides to give the corresponding polyester-grafted VGCF. ${ }^{46}$

\section{Grafting of Poly(p-dioxanone) onto CNT by Surface Initiated Ring-opening Polymerization}

Ring-opening polymerization of $p$-dioxanone is usually initiated by a metal-alkoxide species, derived from alkoxide-ligand exchange reaction. In the case of tin(II) 2-ethylhexanoate $\left(\mathrm{Sn}(\mathrm{Oct})_{2}\right)$, polymerization is initiated by a $\mathrm{Sn}(\mathrm{OR})$ species. ${ }^{76}$ Yoon et al. reported the grafting of biodegradable poly ( $p$-dioxanone) onto shortened SW-CNT by surface initiated ring-opening polymerization of $p$-dioxanone in three steps [Scheme 11(1), (2), and (3)]; ${ }^{77}$ (1) chemical preparation of shorted SW-CNT, (2) covalent attachment of a polymerization initiator to the SW-CNT, and (3) surface initiated ring-opening polymerization.

They point out that the intrinsic properties of poly- 


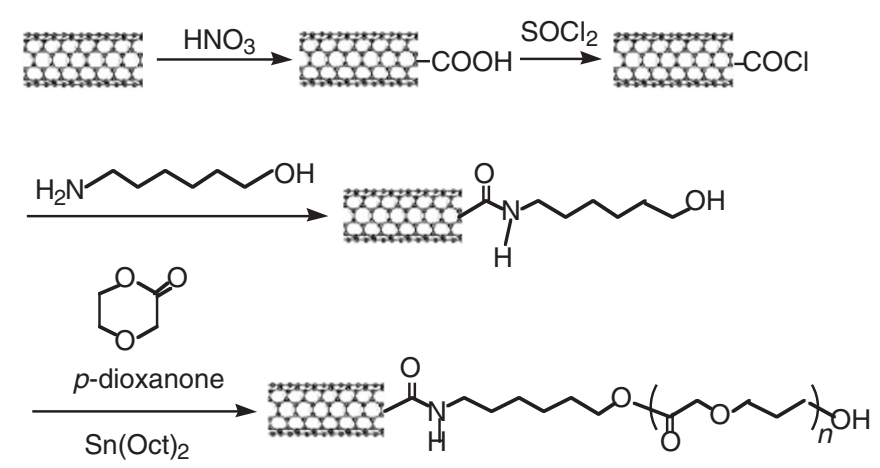

Scheme 11.

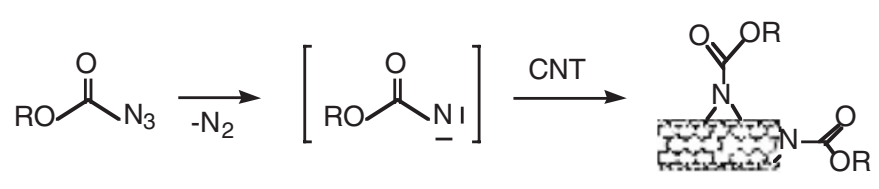

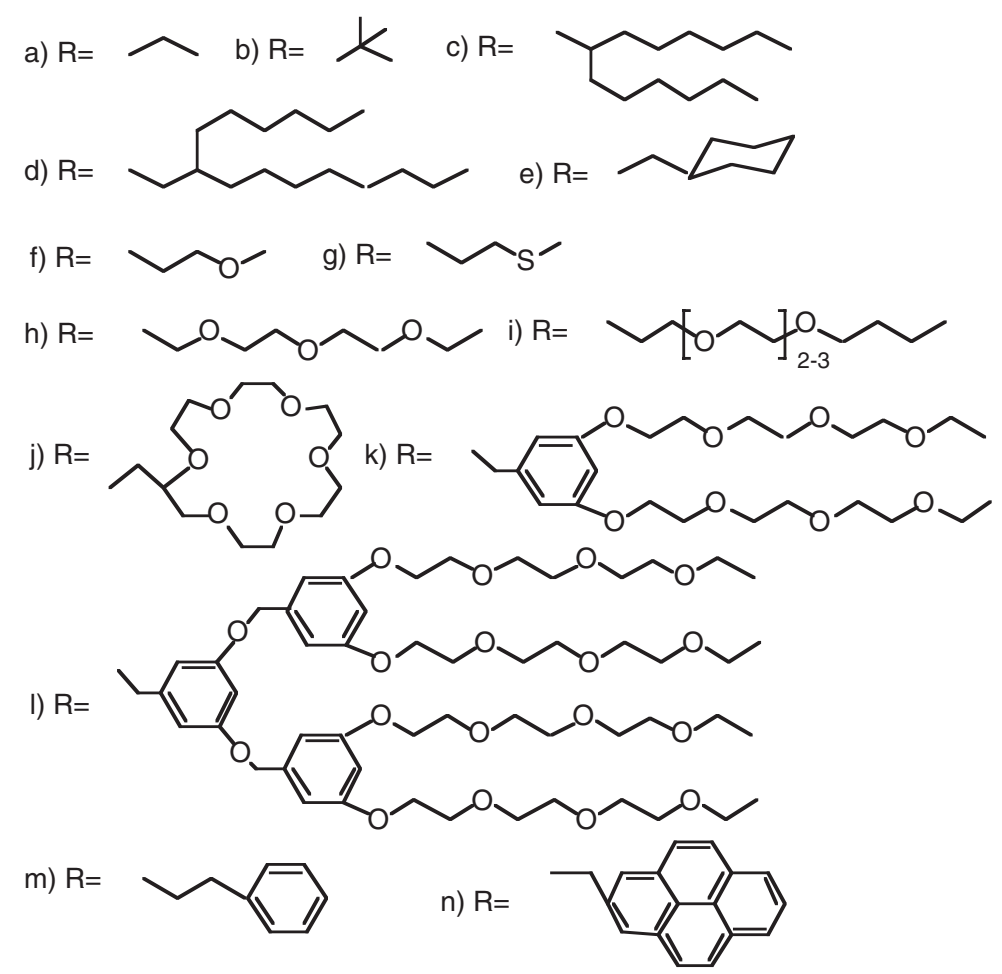

Scheme 12.

( $p$-dioxanone) can be changed by interaction between polymers and CNTs, and interaction was strengthened more by the surface initiated grafting of the polymer than the simple mixing.

\section{GRAFTING OF POLYMERS ONTO CARBON NANOTUBE AND NANOFIBER BY THE OTHER REACTIONS}

Grafting of Polymers by the Reaction with Azide Compounds

Grafting of polymers onto SW-CNT via addition of
(R-)oxycarbonyl nitrenes allows for covalent bonding of various functional groups such as alkyl chains, aromatic rings, dendrimers, crown ethers, and oligoethylene glycol as shown in Scheme $12 .{ }^{78}$ The polymer-grafted SW-CNT gave a stable dispersion in various solvents. AFM and TEM indicated that the grafted SW-CNT forms thin bundles with typical diameter of $10 \mathrm{~nm}$.

The grafting of polystyrene with controlled molecular weight and narrow molecular weight distribution was grafted onto SW-CNT by SW-CNT with polystyrene having terminal azide groups. Polystyrene 
having terminal azide groups was prepared by reaction of sodium azide with bromine terminated polystyrene obtained from ATRP. ${ }^{63}$

\section{Grafting of Polymers by Direct Friedel-Crafts Reac- tion}

We grafted polymers onto carbon black surface by Friedel-Crafts reaction of chlorine-terminated polymers with aromatic rings of carbon black in the presence of $\mathrm{AlCl}_{3} \cdot{ }^{79}$ Recently, Baek and his coworkers reported the in-situ polymerization of 3-phenoxybenzoic acid in the presence of VGCF in poly(phosphoric cid) (PAA)/phosphorus pentoxide medium. ${ }^{80}$ In the polymerization via Friedel-Crafts acylation, poly(oxy-1,3-phenylenecarbonyl-1,4-phenylene was grafted onto VGCF surface. They point out that PAA is quite effective in dispersing VGCF because of its acidic and viscous character.

\section{GRAFTING OF POLYMERS ONTO CARBON NANOTUBE AND NANOFIBER BY ELECTRO CHEMICAL POLYMERIZATION}

Baibarac and his coworkers reported the covalent functionalization of SW-CNT by aniline electrochemical polymerization (Scheme 13). ${ }^{81}$ They investigated the electropolymerization of aniline in $\mathrm{HCl}$ solutions onto SW-CNT film and pointed out that the covalent functionalization of SW-CNT with polyaniline is obtained in two ways. The first is electrochemical polymerization of aniline on SW-CNT film using $\mathrm{HCl}$ solution which results in composites on the type of polyaniline (leuucoemeraldine base) and polyaniline (emeraldine base) functionalized SW-CNT. The second is $\mathrm{NH}_{4} \mathrm{OH}$ post treatment on polyaniline functionalized SW-CNT and involves internal redox reaction between polyaniline (emeraldine base) and SW-CNT, which transforms the polymer chain from the semi-oxidized state into a reduced one.

Feng et al..$^{82}$ and Wu et $a l .{ }^{83}$ reported the preparation of polyaniline/MW-CNT composite via in-situ chemical oxidation polymerization of aniline.

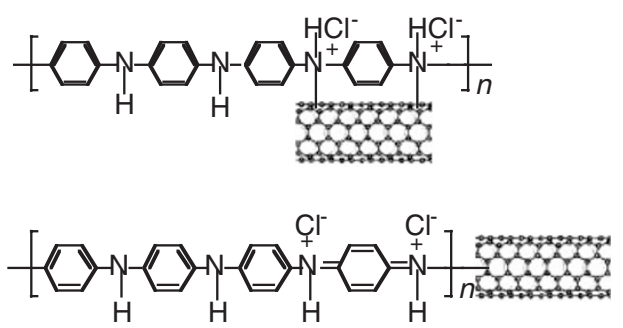

Scheme 13.

\section{GRAFTING REACTION OF CARBOXYL GROUPS ON CARBON NANOTUBE WITH FUNCTIONAL POLYMERS}

\section{Grafting of Dendrimer and Dendron onto CNT}

Sano et al. reported the construction of shortened CNT "stars" with dendrimers. ${ }^{84}$ The carboxyl groups on SW-CNT were converted to acyl chloride groups by treatment with thionyl chloride. The SW-CNT having acyl chloride groups was reacted with terminal amino groups of poly(amidoamine) (PAMAM) starburst dendrimer (tenth generation) [Scheme 14(a)]. AFM on cast film of the reaction mixture on mica indicated star-shaped objects. The average spine length is approximately $0.8 \mu \mathrm{m}$, which agrees well with the length of SW-CNT. This indicates that the acyl chloride groups at the open ends of shortened SWCNT are more reactive than those at the side-wall, although carboxyl groups are present at the side-wall and open ends.

Sun and his coworkers reported the functionalization of SW-CNT and MW-CNT by lipophilic and hydrophilic dendron species under classical amidation and esterification reaction as shown in Scheme 14(b). ${ }^{85,86}$ Lipophilic dendron-grafted CNTs are soluble in hydrocarbon and weakly polar organic solvents, while CNT grafted with oligomeric PEG moieties are soluble in both organic solvents and water.

\section{Grafting of Hydroxyl-terminated Polymers onto CNT}

Poly(vinyl alcohol) (PVA) was grafted onto SWCNT by reaction of surface carboxyl groups with PVA in the presence of a condensing agent such as DCC [Scheme 14(c)]. PVA-grafted SW-CNT composite films are of high optical quality, without any observable phase separation. ${ }^{87}$

We grafted hydroxyl terminated polymers, such as PEG and PE- $b$-PEO, onto MW-CNT and VGCF by direct condensation reaction of carboxyl groups, previously introduced by the ligand-exchange reaction, in the presence of DCC. . $^{37,38}$

\section{Grafting of Amino-terminal Polymers}

The grafting of MW-CNT with amino polymers, such as poly(propenylethyleneimine-co-ethyleneimine) random copolymer, by reaction with acid chloride groups on the surface has been reported. ${ }^{88,89}$ The polymer-grafted MW-CNT thus obtained was also soluble in many common organic solvents and in water.

Zhao et al. reported that poly $(m$-aminobenzene sulfonic acid) (PABS) was grafted onto SW-CNT by reaction with SW-CNT having acid chloride groups to give water soluble SW-CNT as shown in Scheme 14(d). ${ }^{90}$ The PABS-grafted SW-CNT exhibits an order 


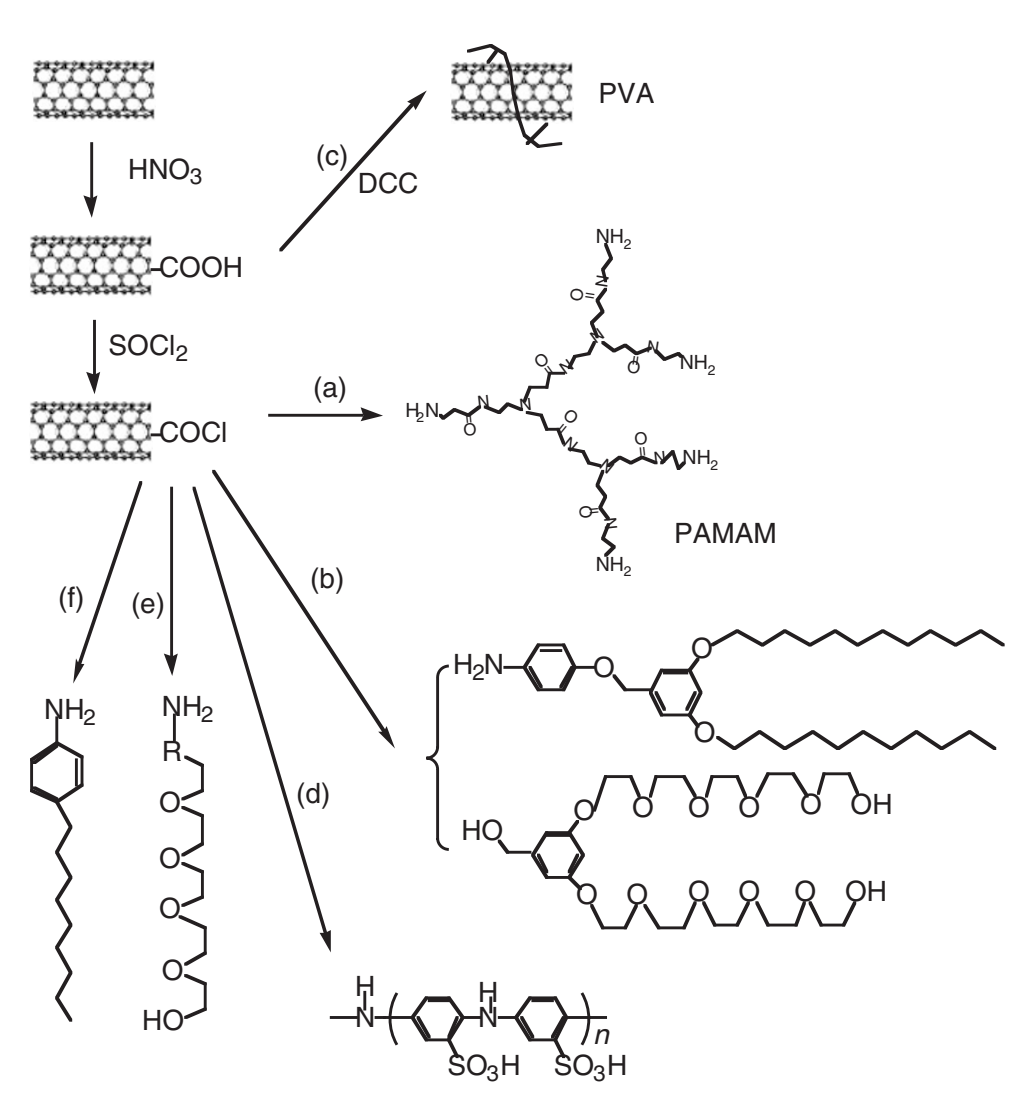

Scheme 14.

of magnitude increase in electrical conductivity over neat PABS.

PEO-grafted SW-CNT was synthesized by reaction of acid-cut SW-CNT with $\mathrm{SOCl}_{2}$, followed by a reaction with monoamine-trerminated PEO. ${ }^{91}$ The conformation of SW-CNT can be controlled by solvent quality and the self-organized structures can be manipurated as if PEO-grafted SW-CNT is an ordinary block copolymer [Scheme 14(e)].

The grafting of long alkyl chains onto short cutted SW-CNT was done by reaction of acyl chloride groups with long chain aliphatic amine, such as octadodecylamine and 4-dodecylaniline [Scheme 14(f)]. ${ }^{92}$

Grafting of Biological Compound, Such as Protein, Enzyme, and DNA onto CNT

Grafting of a biological compound onto CNT to monitor a biochemical event results in promising electrochemical sensors. ${ }^{93}$ Proteins and enzymes can effectively be grafted onto CNT.${ }^{93-96}$ Kerman et al. reported the DNA-direct attachment of MW-CNT using surface acyl chloride groups for enhanced label-free electrochemical detection of DNA hybridization. ${ }^{97}$

Cai et al. reported a novel and sensitive electrochemical DNA biosensor based on MW-CNT with a carboxyl group for covalent DNA immobilization and enhanced hybridization detection. ${ }^{98}$ The sensing mechanism is schematically shown in Scheme 15. A
MW-CNT modified glassy carbon electrode (GCE) was fabricated and oligonucleotides with the $5^{\prime}$-amino group were covalently bonded to the carboxyl group of MW-CNT. The hybridization reaction on the electrode was monitored by differential pulse voltammetry (DPV) analysis using an electroactive intercalator daunomycin as an indicator.

\section{DISPERSIBILITY OF POLYMER-GRAFTED CARBON NANOTUBE AND NANOFIBER}

By grafting of polymers onto CNT and VGCF, dispersibility in good solvents of grafted polymer chain is remarkably improved. Figure 12 shows the dispersibility of PEG-grafted MW-CNT in methanol. Untreated MW-CNT completely precipitated in methanol within $1 \mathrm{~h}$. PEG-grafted MW-CNT gave a stable dispersion in methanol. This indicates that by the grafting of PEG onto MW-CNT surface, the intertwined structure of MW-CNT is effectively destroyed and grafted polymer chains on the side-wall interfere with aggregation of the MW-CNT. ${ }^{37,38}$

Qin reported that the dispersibility of polystyrenegrafted SW-CNT in dichlorobenzene and THF can be controlled by chain length of the grafted polystyrene. ${ }^{63}$

Viswanathan et al. reported that carbanions are introduced onto SW-CNT by treatment with sec-BuLi 


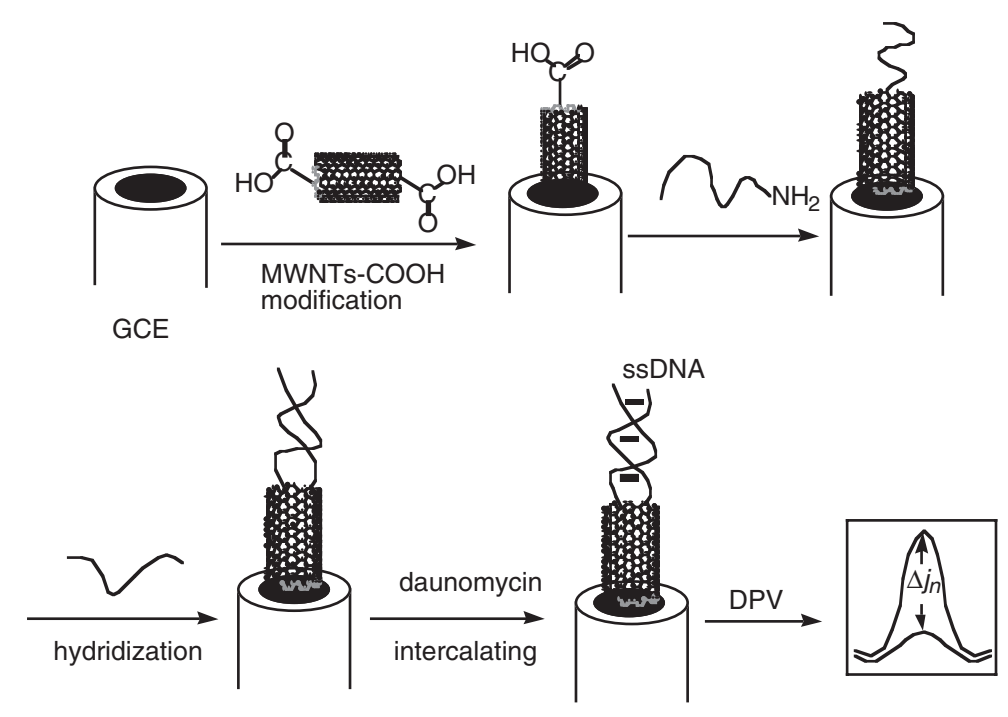

Scheme 15.
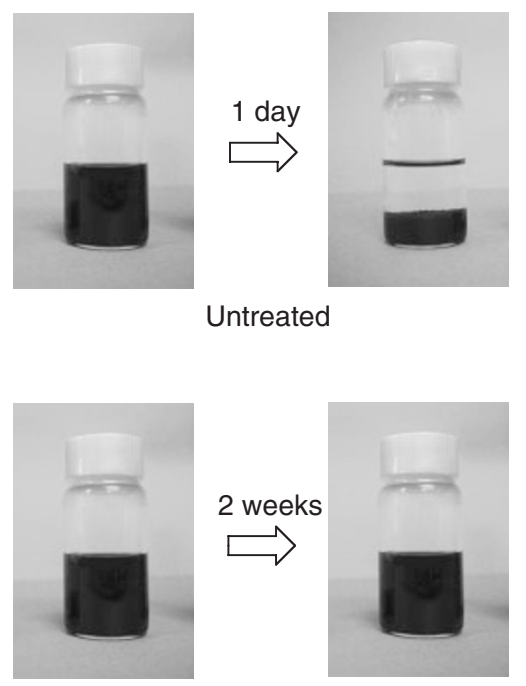

PEG-grafted MW-CNT

Figure 12. Dispersibility of ungrafted and PEG-grafted MWCNT in methanol at room temperature.

that exfoliates the bundle. ${ }^{72}$ Negative charged CNTs are separated from the bundles and disperse in solution due to mutual electrostatic repulsion between individual tubes.

\section{ELECTRIC PROPERTIES OF POLYMER- GRAFTED CARBON NANOTUBE AND NANOFIBER}

Effects of Temperature on the Electric Resistance of Composite from Polymer-grafted VGCF

Vinyl polymer-grafted carbon black, crosslinked with a variety of crosslinking agents, shows a positive temperature coefficient of resistance, i.e., PTC, at temperatures near the glass transition temperature of the grafted polymer. ${ }^{99-101} \mathrm{We}$ reported the effects of

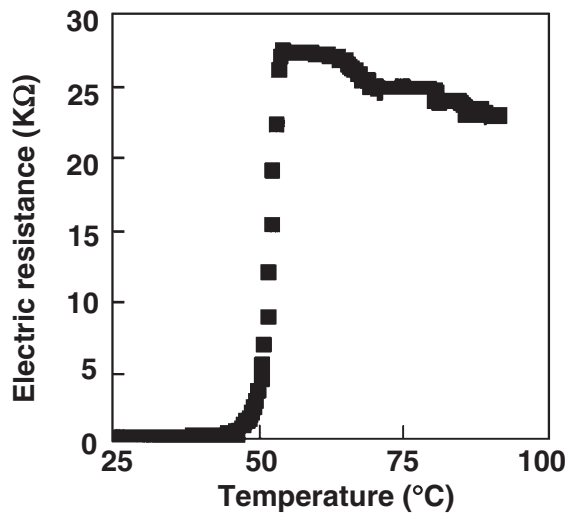

Figure 13. Effects of temperature on the electric resistance of the composite prepared from PEG $\left(M_{\mathrm{n}}=3.4 \times 10^{3}\right)$-grafted VGCF (grafting $=12.4 \%$ ) and PEG $\left(M_{\mathrm{n}}=8.0 \times 10^{3}\right)$. VGCF content $=5.0 \mathrm{wt} \%$.

temperature on the electric resistance of crystalline polymer-grafted carbon black. ${ }^{102}$

Figure 13 shows the effect of temperature on the electric resistance of composite prepared from PEGgrafted VGCF. Electric resistance of the composite from PEG-grafted VGCF drastically increased at melting point of $\mathrm{PEG}, 50^{\circ} \mathrm{C}$. Therefore, the composite from PEG-grafted VGCF shows positive temperature coefficient (PTC) characteristic. ${ }^{37,38}$

The drastic increase of electric resistance of the composite at the melting point of PEG is due to the widening of gaps between VGCFs based on the melting of matrix and grafted PEG.

Effects of Organic Vapor on the Electric Resistance of Composite from Polymer-grafted VGCF

We reported that composites prepared from crystalline polymer-grafted carbon black and crystalline 


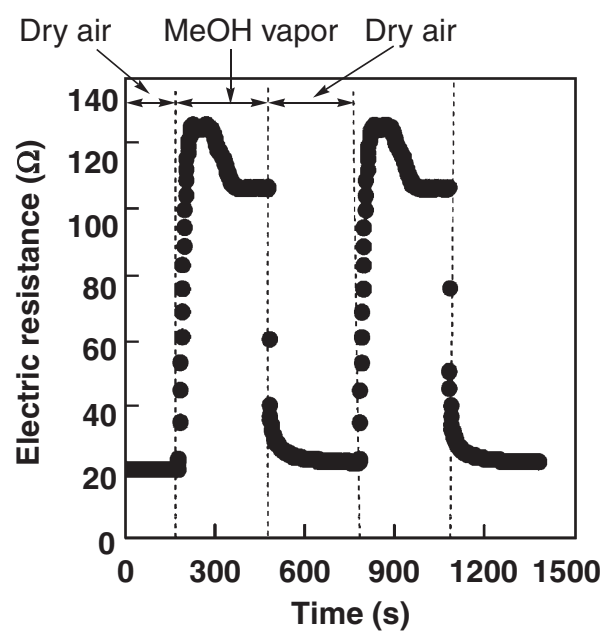

Figure 14. Response of the electric resistance of the composite prepared from PEG $\left(M_{\mathrm{n}}=3.4 \times 10^{3}\right)$-grafted VGCF (grafting $=12.4 \%)$ and PEG $\left(M_{\mathrm{n}}=8.0 \times 10^{3}\right)$ to methanol vapor at $25^{\circ} \mathrm{C}$. VGCF content $=5.0 \mathrm{wt} \%$.

polymer can be used as novel gas sensors. ${ }^{103-108}$ The electric resistance of conductive composites prepared from polymer-grafted CNT and VGCF also respond to various solvent vapors.

Figure 14 shows the electric resistance change of composites prepared from PEG-grafted VGCF and PEG in methanol vapor at $25^{\circ} \mathrm{C}$. The electric resistance of the composite suddenly increased in methanol vapor, and returned immediately to initial resistance when the composite was transferred to dry air. The responsiveness of electric resistance was reproducible even after 20 cycles of exposure to methanol vapor and dry air. ${ }^{37,38}$ The electric resistance of the composite hardly responded to $n$-hexane and acetone vapor, which are poor solvents of PEG.

Figure 15 shows the electric resistance change of the composites prepared from poly(SO-alt-PAn)grafted VGCF and PCL in acetone vapor at $25^{\circ} \mathrm{C}$. The electric resistance of these composites also suddenly increased in acetone, and returned immediately to initial resistance when the composites were transferred to dry air. The responsiveness of electric resistance was also reproducible even after 20 cycles of exposure to acetone vapor and dry air. ${ }^{46}$

This is due to a slight change of gaps between VGCFs based on the absorption of vapor of a good solvent by grafted chain and matrix polymer. Detection of a slight change of crystalline structure of polymer by the absorption of solvent as a large change of electric resistance of the composite may be possible.

\section{CONCLUDING REMARKS}

In this review, recent studies are summarized on the functionalization of carbon nanotubes and nanofibers,

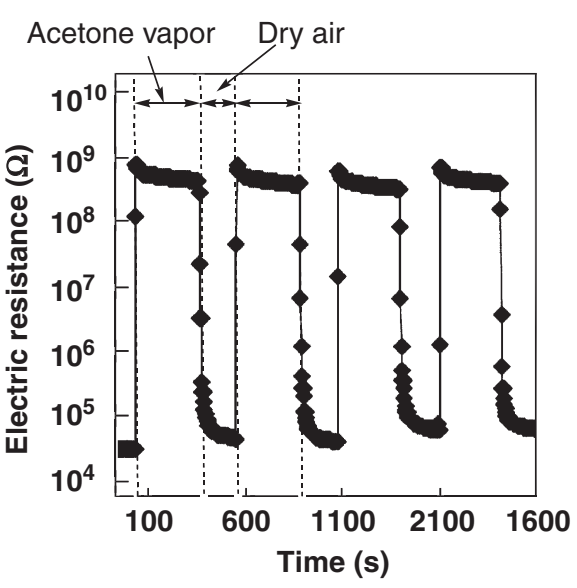

Figure 15. Response of electric resistance of composite prepared from poly(SO-alt-PAn)-grafted VGCF and PCL to acetone vapor at $25^{\circ} \mathrm{C}$. VGCF content $=5.0 \mathrm{wt} \%$.

such as SW-CNT, MW-CNT, CS-CNT, and VGCF, by grafting of polymers. The method for surface grafting of polymers presented here can be applied for the grafting of polymers onto fullerenes ${ }^{109}$ and inorganic particles, ${ }^{110-112}$ such as silica, titanium dioxide, and ferrite, organic pigments, ${ }^{13,114}$ and polymer powders. ${ }^{115,116}$

The solubilization of CNTs by use of $\pi-\pi$ interactions of aromatic compounds and CNT surface and by polymer wrapping of CNTs is also reviewed. ${ }^{117,118}$

Modification of CNT and VGCF surfaces will become more and more important for the design of high performance conductive composite materials. Surface-modified CNT and VGCF by grafting of polymers have a large potential as electrode material for fuel cells and high performance nano-composites.

Acknowledgment. The author thanks all the contributing co-workers and acknowledges the financial support in part by Grant-in-Aid for Scientific Research from the Ministry of Education, Culture, Sports, Science and Technology of Japan.

\section{REFERENCES}

1. P. M. Ajayan, Chem. Rev., 99, 1787 (1999).

2. M. Inagaki, K. Kaneko, and T. Nishizawa, Carbon, 42, 1401 (2004).

3. M. R. Falvo, G. J. Glary, R. M. Taylor, V. Chi, F. P. Brooks, S. Washibuvn, and R. Superfine, Nature, 389, 582 (1977).

4. T. W. Odom, J.-L. Huang, P. Kim, and C. M. Lieber, Nature, 391, 62 (1988).

5. M. S. Dresselhause, G. Gresselhause, and P. Avouris, Ed., "Carbon Nanotubes: Synthesis, Structure, Properties, and Applications, Topics in Applied Physics," Vol. 80, Springer-Verlag, Heidelberg, 2000.

6. L. S. Schadler, S. C. Giannaris, and P. M. Ajayan, Appl. 
Phys. Lett., 73, 3842 (1999).

7. S. J. Park, M. S. Cho, S. T. Lim, H. J. Choi, and M. S. Jhon, Macromol. Rapid Commun., 24, 1070 (2003).

8. T. E. Chang, L. R. Jensen, A. Kisliuuk, R. B. Pipes, R. Pyrz, and A. P. Sokolov, Polymer, 46, 439 (2005).

9. G. G. Tibbetts, G. L. Doll, D. W. Gorkiewic, J. J. Moleski, T. A. Perry, C. J. Dasch, and M. J. Balogh, Carbon, 31, 1039 (1993).

10. M. Endo, K. Takeuchi, T. Furuta, T. Kasai, X. Sun, C. Kiang, and M. Dresselhaus, J. Phys. Chem. Solids, 58, 1702 (1997).

11. L. Piraux, B. Nysten, A. Haquenne, J. Issi, M. S. Dresselhaus, and M. Endo, Solid State Commun., 50, 697 (1984).

12. J. Issi and B. Nysten, "Carbon Fibers," J. B. Donnet, T. Wong, J. Peng, and S. Rebouillat, Ed., Marcel Dekker, New York, N.Y., 1998, p 371.

13. H. Abe, T. Murai, and K. Zaghib, J. Power Sources, 77, 110 (1999).

14. M. Endo, Y. Kim, T. Hayashi, K. Nishimura, T. Matusita, K. Miyashita, and M. Dresselhaus, Carbon, 39, 1287 (2001).

15. N. Tsubokawa, Prog. Polym. Sci., 17, 417 (1992).

16. N. Tsubokawa, Bull. Chem. Soc. Jpn., 75, 2115 (2002).

17. N. Tsubokawa, K. Fujiki, and Y. Sone, Polym. J., 20, 213 (1988).

18. K. Fujiki, N. Tsubokawa, and Y. Sone, Polym. J., 22, 661 (1990).

19. N. Tsubokawa, A. Funaki, Y. Hada, and Y. Sone, J. Polym. Sci., Polym. Chem. Ed., 20, 3297 (1987).

20. N. Tsubokawa, A. Yamada, and Y. Sone, Polym. Bull., 10, 62 (1983).

21. N. Tsubokawa, H. Nunokawa, and Y. Sone, J. Macromol. Sci., Pure Appl. Chem., A23, 105 (1986).

22. N. Tsubokawa, Y. Jian, and Y. Sone, J. Polym. Sci., Polym. Chem. Ed., 26, 2715 (1988).

23. N. Tsubokawa and H. Tsuchida, J. Macromol. Sci., Pure Appl. Chem., A29, 311 (1992).

24. N. Tsubokawa and K. Yanadori, Kobunshi Ronbunshu, 49, 865 (1992).

25. J. B. Donnet, G. Henrich, and G. Majoski, Eur. Polym. J., 7, 1069 (1971).

26. K. Fujiki, K. Magara, N. Tsubokawa, and Y. Sone, J. Soc. Rubber Ind., Jpn., 64, 378 (1991).

27. Y. Wabg, Z. Iquval, and S. Mitra, Carbon, 43, 1015 (2005).

28. R. Barthos, D. Mehn, A. Demortier, N. Pierard, Y. Morciaux, G. Demortier, A. Fonseca, and J. B. Nagy, Carbon, 43, 321 (2005).

29. V. Georgakilas, K. Kordatos, M. Prato, D. M. Guldi, M. Holzinger, and A. Hirsch, J. Am. Chem. Soc., 124, 760 (2002)

30. W. Zhao, C. Song, and P. E. Pehrsson, J. Am. Chem. Soc., 124, 12418 (2002).

31. A. G. Rinzler, J. Lui, H. Dai, P. Nikolaev, C. B. Huffman, F. J. Rodriguez-Macias, P. J. Boul, A. H. Lu, D. Heymann, D. T. Colbert, R. S. Lee, J. E. Fischer, A. M. Rao, P. C. Eklund, and R. E. Smallev, Appl. Phys. A, 67, 29 (1999).

32. K. Esumi, M. Ishigami, and A. Nakajima, Carbon, 34, 279 (1996).
33. P. V. Lakshminarayanan, H. Toghiani, and C. U. Pittman, Jr., Carbon, 42, 2433 (2004).

34. M. Ley and M. Szwarz, J. Chem. Phys., 22, 1621 (1954).

35. M. Hey and G. Williams, Discuss. Faraday Soc., 14, 216 (1953).

36. N. Tsubokawa, N. Abe, G. Wei, J. Chen, S. Saitoh, and K. Fujiki, J. Polym. Sci., Part A: Polym. Chem., 40, 1868 (2002).

37. N. Tsubokawa, Special Issue of 3rd International Symposium on High-Tech Polymer and Polymeric Complexes, Northwest Normal University, Lanzhou, China, 2004, p 16.

38. G. Wei, S. Saitoh, H. Saitoh, K. Fujiki, T. Yamauchi, and N. Tsubokawa, Polymer, 45, 8723 (2004).

39. A. N. Nesmeyanov, N. A. Vol'kenau, and I. N. Bolesova, Dokl. Akad. Nauk, 149, 615 (1963).

40. A. N. Nesmeyanov, N. A. Vol'kenau, and I. N. Bolesova, Tetrahedron Lett., 1725 (1963).

41. A. N. Nesmeyanov, N. A. Vol'kenau, and I. N. Bolesova, Dokl. Akad. Nauk, 160, 1327 (1965).

42. N. Nesmeyanov, N. A. Vol'kenau, and I. N. Bolesova, Dokl. Akad. Nauk, 166, 607 (1966).

43. A. N. Nesmeyanov, N. A. Vol'kenau, E. I. Sirotkina, and V. V. Deryabin, Dokl. Akad. Nauk, 177, 1110 (1967).

44. E. I. Sirotkina, N. A. Vol'kenau, and A. N. Nesmeyanov, Izv. Akad. Nauk, Ser. Khim., 1524 (1969).

45. M. Miyake, K. Yasuda, T. Kashihara, and T. Teranishi, Chem. Lett., 1037 (1999).

46. G. Wei, K. Fujiki, H. Saitoh, K. Shirai, and N. Tsubokawa, Polym. J., 36, 316 (2004).

47. G. Wei, K. Shirai, Fujiki, H. Saitoh, T. Yamauchi, and N. Tsubokawa, Carbon, 42, 1923 (2004).

48. N. Tsubokawa and M. Hosoya, React. Polym., 14, 33 (1991).

49. N. Tsubokawa, Nippon Kagaku Kaishi, 1012 (1993).

50. K. Ohkita, N. Tsubokawa, E. Saitoh, M. Noda, and N. Takashima, Carbon, 13, 443 (1975).

51. K. Ohkita, N. Tsubokawa, and E. Saitoh, Carbon, 16, 41 (1978).

52. N. Tsubokawa and K. Yanadori, Kobunshi Ronbunshu, 49, 865 (1992).

53. N. Tsubokawa and S. Handa, J. Jpn. Soc. Color Mater., 66, 468 (1993).

54. X. Lou, C. Detrembleur, V. Sciannamea, C. Pangnoulle, and R. Jerome, Polymer, 45, 6097 (2004).

55. Lou, C. Detrembleur, V. Sciannamea, C. Pangnoulle, and R. Jerome, Adv. Mater., 16, 2123 (2004).

56. V. Datsyuk, C. G-Piecourt, S. Dagreou, L. Billon, J.-C. Dupin, E. Flahaut, A. Peigney, and C. Laurent, Carbon, 43, 873 (2005).

57. J. Chen, H. Iwata, N. Tsubokawa, Y. Maekawa, and M. Yoshida, Polymer, 43, 2201 (2002).

58. S. Suyama, Y. Sugihara, Y. Watanabe, and T. Nakamura, Polym. J., 24, 971 (1992).

59. S. Hayashi, S. Handa, and N. Tsubokawa, J. Polym. Sci. Part A: Polym. Chem., 34, 1589 (1996).

60. Y. Takahashi, S. Yoshida, K. Fujiki, T. Yamauchi, and N. Tsubokawa, The 8th SPSJ International Polymer Conference, submitted (2005). 
61. H. Kong, C. Gao, and D. Yan, J. Am. Chem. Soc., 126, 412 (2004).

62. S. Quin, W. T. Ford, D. E. Resasco, and J. E. Herrera, J. Am. Chem. Soc., 126, 170 (2004).

63. S. Quin, D. Quin, W. T. Ford, D. E. Resasco, and J. E. Herrera, Macromolecules, 37, 725 (2004).

64. C. H. Bamford, G. C. Eastmond, and F. J. T. Fildes, Proc. R. Soc. London, Ser. A, 326, 431 (1972).

65. C. H. Bamford and I. P. Middleton, Eur. Polym. J., 19, 1027 (1983).

66. C. H. Bamford, G. C. Eastmond, and W. R. Maltman, Trans. Faraday Soc., 62, 2531 (1966).

67. C. H. Bamford, I. P. Middleton, K. G. Al-Lamee, and J. Paprotny, Brit. Polym. J., 19, 269 (1987).

68. Y. Shirai and N. Tsubokawa, React. Funct. Polym., 32, 153 (1997).

69. Y. Shirai, K. Shirai, and N. Tsubokawa, J. Polym. Sci., Part A: Polym. Chem., 39, 2157 (2001).

70. S. J. Park, M. S. Cho, S. T. Lim, H. J. Choi, and M. S. Jhon, Macromol. Rapid Commun., 24, 1070 (2003).

71. W. Wu, S. Zhang, Y. Li, J. Li, Y. Qui, Z.-X. Guo, Dai, C. Ye, and D. Zhu, Macromolecules, 36, 6286 (2003).

72. G. Visvanathan, N. Chakrapan, H. Yang, B. Wei, H. Chung, K. Cho, C. Y. Ryu, and P. M. Ajayan, J. Am. Chem. Soc., 125, 9258 (2003).

73. N. Tsubokawa, A. Yamada, and Y. Sone, Polym. Bull., 10, 62 (1983).

74. N. Tsubokawa, A. Yamada, and Y. Sone, Polym. J., 16, 333 (1984)

75. N. Tsubokawa, A. Yamada, and Y. Sone, Kobunshi Ronbunshu, 42, 509 (1985).

76. A. Kowalski, A. Duda, and S. Penkzek, Macromolecules, 33, 7359 (2000).

77. K. R. Yoon, W.-J. Kim, and I. S. Choi, Macromol. Chem. Phys., 205, 1218 (2004).

78. M. Hoizinger, J. Abraham, P. Whelan, R. Graupner, L. Ley, F. Hennrich, M. Kappes, and A. Hirsch, J. Am. Chem. Soc., 125, 8566 (2003).

79. N. Tsubokawa, M. Muramatsu, and K. Fujiki, J. Jpn. Soc. Color Mater., 66, 405 (1993).

80. J. Baek, C. Lyons, and L.-S. Tan, Macromolecdules, 37, 8278 (2004).

81. M. Baibrac, I. Baltog, C. Godon, S. Lefrant, and O. Chauvet, Carbon, 42, 3143 (2004).

82. W. Feng, X. D. Bai, Y. Q. Liang, X. G. Wang, and K. Yoshino, Carbon, 41, 1551 (2003).

83. T. Wu, Y. Lin, and C. Liao, Carbon, 43, 734 (2004).

84. M. Sano, A. Kamino, and S. Shinkai, Angew. Chem. Int. Ed., 40, 4661 (2001).

85. Y. Sun, W. Huang, Y. Lin, K. Fu, A. Kitaygorodskiy, L. A. Riddle, Y. J. Yu, and D. L. Carroll, Chem. Mater, 13, 2864 (2001).

86. Y. Sun, K. Fu, Y. Lin, and W. Huang, Acc. Chem. Res., 35, 1096 (2002).

87. Y. Lin, B. Zhou, K. A. S. Fernando, P. Liu, L. F. Allard, and Y. Sun, Macromolecules, 36, 7199 (2003).

88. Y. Lin, A. M. Rao, B. Sadanadan, E. A. Kenik, and Y. Sun, J. Phys. Chem. B., 106, 1294 (2002).

89. R. Czerw, Z. Guo, P. M. Ajayan, Y. Sun, and D. L. Carroll,
Nano Lett., 1, 423 (2001).

90. B. Zhao, H. Hu, and R. C. Haddon, Adv. Funct. Mater., 14, 71 (2004).

91. M. Sano, A. Kamino, J. Okamura, and S. Shinkai, Langmuir, 17, 5125 (2001).

92. M. A. Hamon, J. Chen, H. Hu, Y. Chen, M. E. Itkis, A. M. Rao, P. C. Eklund, and R. C. Haddon, Adv. Mater., 11, 834 (1999).

93. Q. Zhao, Z. Gan, and Q. Zhuang, Electroanalysis, 14, 1609 (2002).

94. F. Balavoine, P. Schultz, C. Richard, V. Malluoh, T. W. Ebbesen, and C. Mioskowski, Angew. Chem. Int. Ed., 38, 1912 (1999).

95. J. J. Davis, R. J. Coles, and H. A. O. Hill, J. Electroanal. Chem., 440, 279 (1997).

96. J. J. Davis, M. L. H. Green, O. Hill, C. Y. Leung, P. J. Sadler, J. Sloan, A. V. Xavier, and S. C. Tsang, Inorg. Chim. Acta, 272, 261 (1998).

97. K. Kerman, Y. Morita, Y. Takamura, M. Ozsoz, and E. Tamiya, Electroanalysis, 16, 1667 (2004).

98. H. Cai, X. Cao, Y. Jiang, P. He, and Y. Fang, Anal. Bioanal. Chem., 375, 287 (2003).

99. K. Ohkita, "Grafting of Polymers onto Carbon Black," Polymer Digest Co., Tokyo, 1983, p 122.

100. J. Meyer, Polym. Eng. Sci., 13, 462 (1973).

101. S. Miyauchi and T. Togashi, J. Appl. Polym. Sci., 30, 2743 (1985).

102. S. Hayashi, A. Naitoh, S. Machida, M. Okazaki, K. Maruyama, and N. Tsubokawa, Appl. Organomet. Chem., 12, 743 (1998).

103. N. Tsubokawa, S. Yoshikawa, K. Maruyama, T. Ogasawara, and K. Saitoh, Polym. Bull., 39, 217 (1997).

104. M. Okazaki, K. Maruyama, M. Tsuchida, and N. Tsubokawa, Polym. J., 31, 972 (1999).

105. J. Chen and N. Tsubokawa, Polym. Adv. Technol., 11, 101 (2000).

106. J. Chen and N. Tsubokawa, J. Appl. Polym. Sci., 77, 2437 (2000).

107. J. Chen and N. Tsubokawa, Polym. J., 32, 729 (2000).

108. J. Chen and N. Tsubokawa, J. Macromol. Sci., Pure Appl. Chem., A38, 383 (2001).

109. H. Wakai, S. Yoshida, T. Shinno, H. Kikuchi, T. Yamauchi, and N. Tsubokawa, Polym. Prepr., Jpn., 53, 2844 (2004).

110. N. Tsubokawa, J. Jpn. Soc. Color Mater., 71, 656 (1998).

111. N. Tsubokawa, "Fundamental and Applied Aspects of Chemically Modified Surfaces,” J. P. Blitz and C. B. Little, Ed., The Royal Society Chemistry, Cambridge U.K., 1999, p 36.

112. Y. Cohen, W. Yoshida, V. Nguyen, N. Bei, and J. Jou, "Oxide Surfaces," J. A. Wingrave, Ed., Marcel Dekker, New York, N.Y., 2001, p 321.

113. S. Yoshikawa, T. Iida, and N. Tsubokawa, Prog. Org. Coat., 31, 127 (1977).

114. N. Tsubokawa, M. Kobayashi, and T. Ogasawara, Prog. Org. Coat., 36, 39 (1999).

115. S. Yoshikawa, T. Takayama, and N. Tsubokawa, J. Appl. Polym. Sci., 68, 1883 (1998).

116. N. Tsubokawa and T. Oyanagi, J. Polym. Sci., Part A: 
Polym. Chem., 31, 1633 (1993).

117. N. Nakajima, J. Soc. Rubber Ind., Jpn., 77, 414 (2004).
118. N. Nakajima and Y. Tomonari, Kobunshi Kako, 54, 34 (2005).

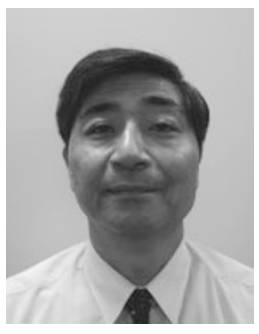

Norio Tsubokawa was born in 1947 in Toyama Prefecture, Japan. He received his M. S. Eng. from Niigata University in 1972. He was appointed research associate of Department of Applied Chemistry, Faculty of Engineering at Niigata University in 1972. He received his Ph. D. degree in 1982 from Tokyo Institute of Technology. He was promoted to Associate Professor of the same Department in 1988 and to Professor of Department of Material Science and Technology, Faculty of Engineering at Niigata University in 1995. He has received several awards, including the Toyama Award (1990), the Award of Society of Rubber Industry, Japan, for the Outstanding Paper published in the Journal of Society of Rubber Industry, Japan (1991), the Award of Japan Society of Color Material, Japan, for the Outstanding Paper published in the Journal of Japan Society of Color Material (1993), Ishikawa Carbon Award (1995), and Nakanishi Memorial Award (2002). His research has been focused on the surface modification and functionalization of nano-sized particles and nanocarbons by grafting of polymers. 